University of Louisville

ThinkIR: The University of Louisville's Institutional Repository

\title{
Effect of finger rings on microbial cross-contamination during dental clinical procedures.
}

Swapna Nadikuda

University of Louisville

Follow this and additional works at: https://ir.library.louisville.edu/etd

\section{Recommended Citation}

Nadikuda, Swapna, "Effect of finger rings on microbial cross-contamination during dental clinical procedures." (2010). Electronic Theses and Dissertations. Paper 1035.

https://doi.org/10.18297/etd/1035

This Master's Thesis is brought to you for free and open access by ThinkIR: The University of Louisville's Institutional Repository. It has been accepted for inclusion in Electronic Theses and Dissertations by an authorized administrator of ThinkIR: The University of Louisville's Institutional Repository. This title appears here courtesy of the author, who has retained all other copyrights. For more information, please contact thinkir@louisville.edu. 


\title{
EFFECT OF FINGER RINGS ON MICROBIAL CROSS-CONTAMINATION DURING DENTAL CLINICAL PROCEDURES
}

\author{
By \\ Swapra Nadikuda, BDS \\ A Thesis \\ Submitted to the Faculty of the \\ University of Louisville \\ School of Dentistry \\ in Partial Fulfiliment of the Requirements \\ for the Degree of \\ Master of Science in Oral Biology
Department of Oral Health and Rehabilitation
University of Louisville
School of Dentistry
Louisville, Kentucky

August 2010 
Copyright 2010 by Swapna Nadikuda

All rights reserved 



\title{
EFFECT OF FINGER RINGS ON MICROBIAL CROSS-CONTAMINATION DURING DENTAL CLINICAL PROCEDURES
}

\author{
By \\ SWAPNA NADIKUDA \\ BDS, 2005 \\ Rajiv Gandhi University of Health Sciences \\ Mysore, Karnataka, India
}

A Thesis Approved on

August 6, 2010

by the following thesis committee:

Lawrence Gettleman, DMD, MSD

Thesis Director

Robert Staat, PhD

Ruth Carrico, $\mathrm{PhD}$

Douglas J. Lorenz, MS, MSPH 


\section{DEDICATION}

This dissertation is dedicated to my parents,

Mr. Ramchandar Rao Nadikuda

and

Mrs. Radha Nadikuda

who have given me invaluable educational opportunities. 


\section{ACKNOWLEDGMENTS}

I am grateful to those who made this thesis possible and who have contributed much effort to this paper. I thank the committee members: Robert Staat for teaching me methods of culturing the bacteria and helping me to work in the lab; Douglas Lorenz, who made my work easier by the doing statistical analysis for my project; and Ruth Carrico, for her comments and assistance over the past one and a-half years. Dr. Douglas Darling was most helpful as we designed this scientific study, and Dr. David A. Scott has mentored me in my studies as director of the MS in Oral Biology program. I owe my deepest gratitude to my mentor/advisor, Dr. Lawrence Gettleman, for his guidance and patience. His support and encouragement made me to learn and work more effectively on the clinical research, and he was always there to listen and give advice. He has been a friend and mentor to me.

I express my thanks to my father Mr. Ramchandar Rao Nadikuda, who is a role model to me and my mother, Mrs. Radha Nadikuda. My heartiful thanks to my husband, Ramesh Nimmanagoti, for understanding encouraging and always being with me. Also, many thanks to the members of my family Rama Rao Kolluru, Sudha Kolluru, Surekha Nadikuda, Mahesha Basava, Sridhar Nadikuda, Balaji Nadikuda. 


\title{
ABSTRACT \\ EFFECT OF FINGER RINGS ON MICROBIAL CROSS-CONTAMINATION DURING DENTAL CLINICAL PROCEDURES
}

\author{
SWAPNA NADIKUDA
}

\begin{abstract}
AUGUST 6, 2010
CDC/WHO only "recommends" that rings be removed under gloves because of cross-contamination between health care workers and patients. Microbiological samples of oral streptococci beneath rings and between fingers under non-sterile exam gloves were taken before and after dental procedures (before and after washing with antimicrobial soap) from 50 junior/senior dental students. Subjects wore two rings on one hand, with none on the other (control). Rings were worn on the opposite hand at another session. Handedness, glove tears, and leaks, were also measured.

There were significant glove tears and leakage in the glove on the dominant hand, especially when wearing rings (experimental). $79.8 \%$ of right and $70.5 \%$ of left gloves were torn and $70.3 \%$ of students used cold water to wash. Wearing rings with/without stones, perforations, or sharp edges under nitrile gloves while performing dental treatment procedures retained oral streptococci even after the post-wash. Wearing rings under gloves should be prohibited.
\end{abstract}




\section{TABLE of CONTENTS}

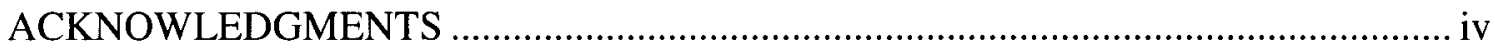

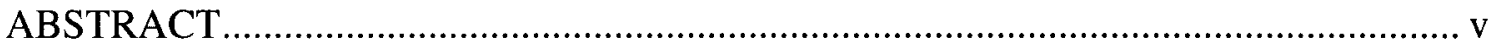

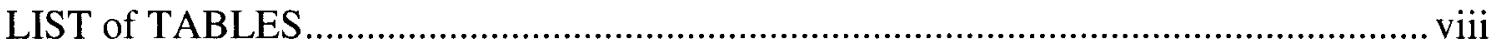

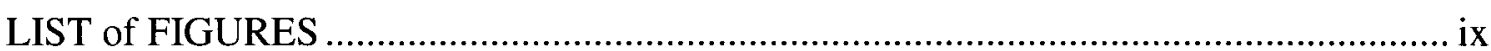

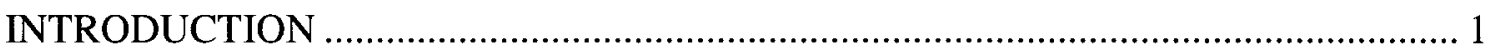

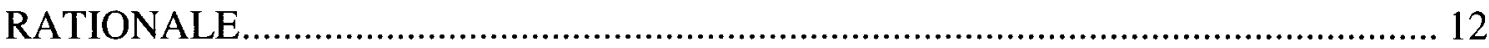

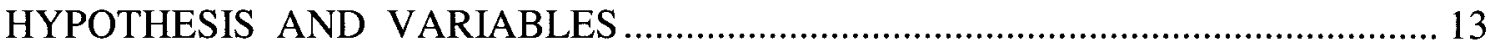

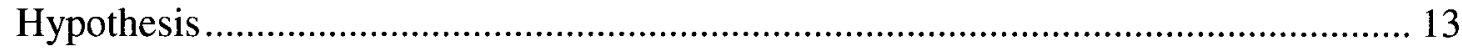

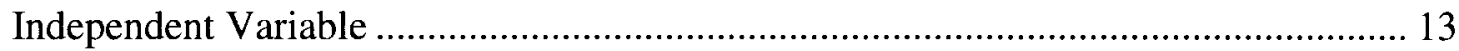

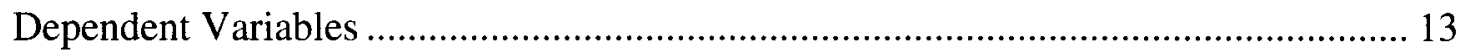

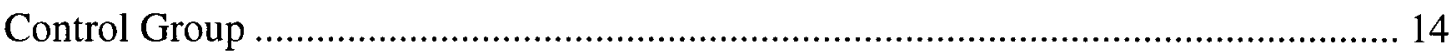

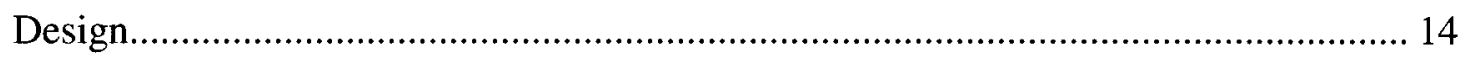

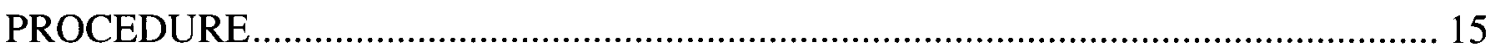

Criteria for Dental Student Subjects.................................................................... 15

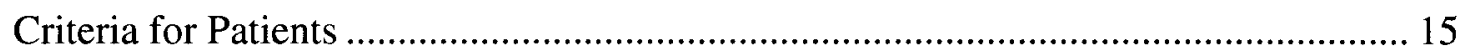

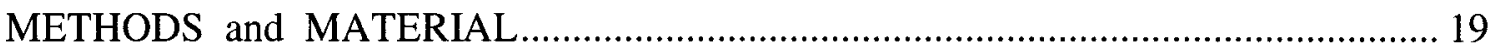

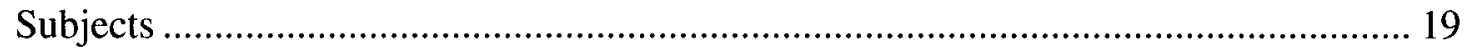

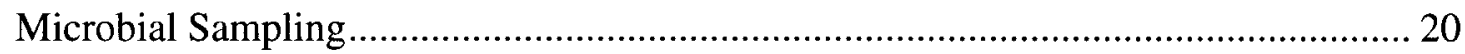

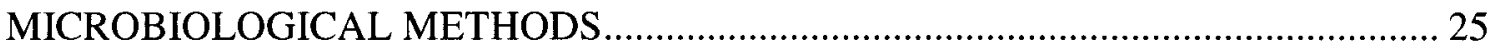




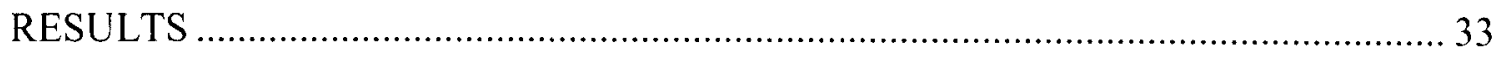

I. Analysis of Contamination - Contamination Defined as >0 Count .......................... 38

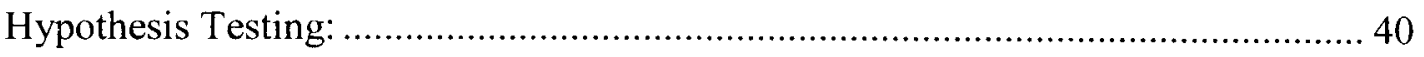

II. Analysis of Contamination - Contamination Defined as $\geq 10$ Count ..................... 41

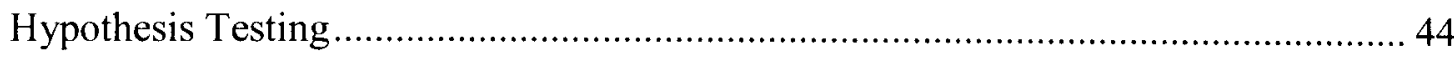

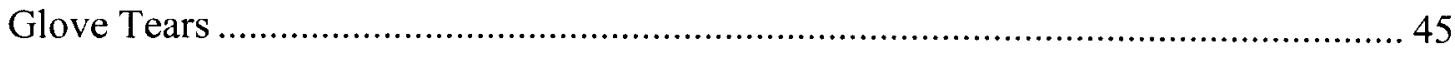

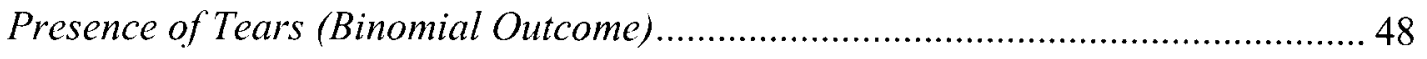

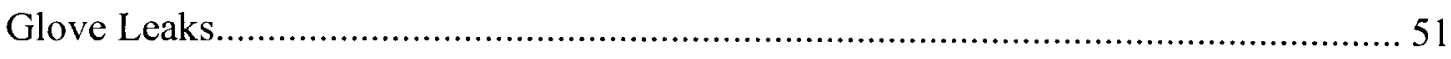

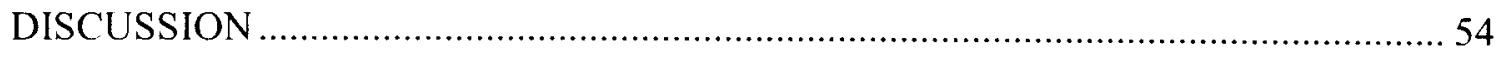

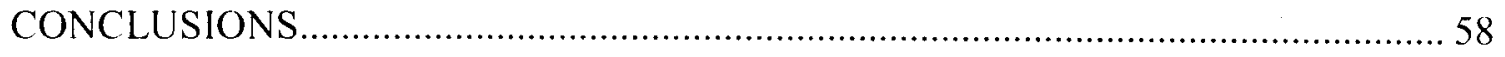

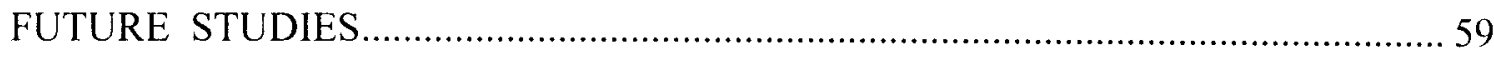

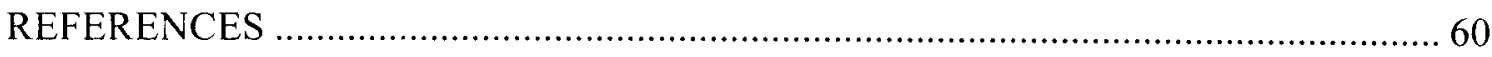

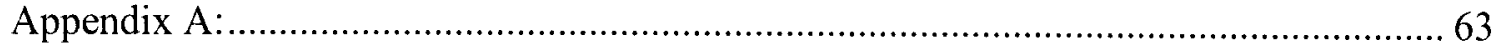

Appendix B:

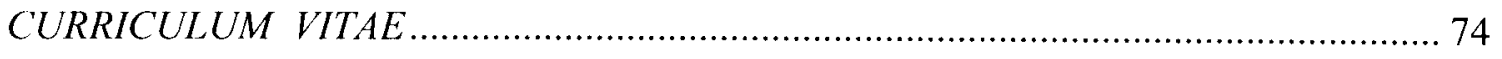




\section{LIST of TABLES}

TABLE

PAGE

Table 1. Summary of all data collected. 34

Table. 2 Samples contaminated with Streptococcus spp. with values $\geq 0$................... 37

Table. 3 Samples contaminated with Streptococcus spp. with values $\geq 10 \ldots \ldots \ldots \ldots \ldots \ldots . . . . . . . .42$

Table 4. Values in the table are raw averages of tear size ...................................... 47

Table 5. Values in the table are raw averages of the presence of tears........................ 49

Table 6. Values in the table are raw averages of the leak size...................................5 52 


\section{LIST of FIGURES}

FIGURE

PAGE

Figure 1. Common sites of glove perforation ........................................................... 10

Figure 2. Men's and women's stainless steel rings..................................................... 17

Figure 3. Investigator's nitrile-gloved hand with rings …............................................. 17

Figure 4. Examples of stainless steel rings on the index finger and ring finger.............. 18

Figure 5. Sample swab used to measure the presence of microbes................................ 22

Figure 6. Microbial sample swab in interphalangeal spaces............................................ 22

Figure 7. PROVON ${ }^{\circledR}$ Antimicrobial Lotion Soap........................................................23

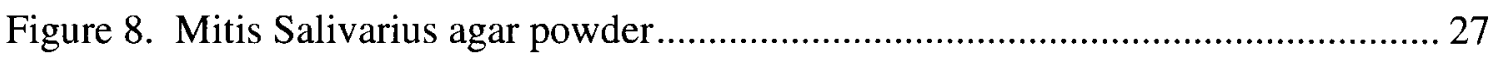

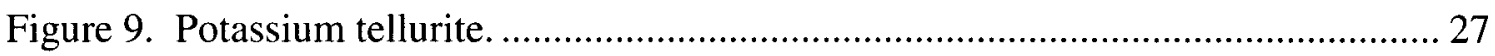

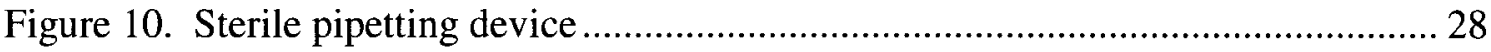

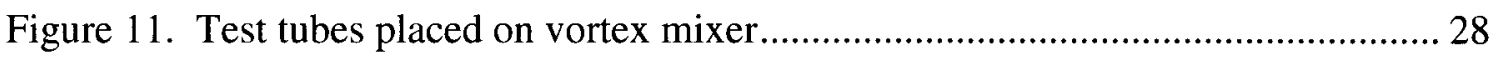

Figure 12. Sterile pipette tips, pipettor, and quadrant Petri dishes medium................... 29

Figure 13. Delivering aliquot into quadrant Petri dishes.............................................. 29

Figure 14. Covered Petri dishes in incubator aerobic conditions. .................................. 30 


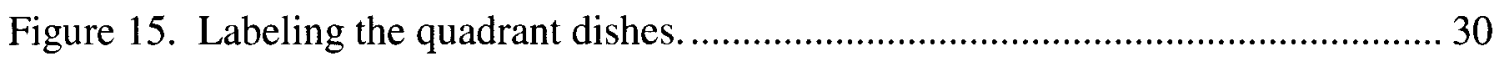

Figure 16. Quadrant Petri dishes with Mitis Salivarius agar + potassium tellurite right. 31

Figure 17. Counting oral streptococci spp. By two investigators.................................... 32

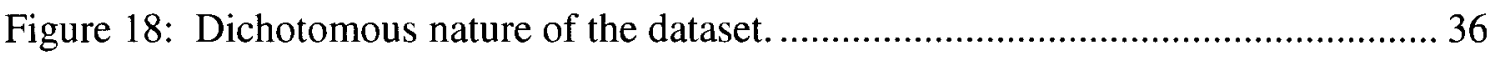

Figure 19. Raw data plot in percent of samples contaminated for all data ..................... 39

Figure 20. Raw data plot of all samples for dominant hand and dependant hand........... 43 


\section{CHAPTER I}

\section{INTRODUCTION}

Based on scientific rationale, the U.S. Centers for Disease Control and Prevention (CDC) found that finger rings increase bacterial contamination and transmission of pathogens in health-care settings from patients to health care personnel and vice versa and from patients to patients (Centers for Disease Control and Prevention, 2002). Yet they only make a "recommendation" to remove finger rings, before donning gloves, citing conflicting evidence in the literature, and call for more research on wearing jewelry during clinical procedures.

Other organizations like the U.S. Occupational Safety and Health Administration, the U.S. Food and Drug Administration, and the U.S. Environmental Protection Agency make it compulsory to remove all jewelry, whereas the CDC only makes it a "recommendation." It has not issued a mandatory rule when conducting medical or dental clinical procedures (Harte, 2004).

We find that the evidence is overwhelming in favor or ring removal, and have conducted the present study to measure cross-contamination from patients to HCWs in a dental setting.

We feel that there are five reasons not to wear rings in a health care setting when wearing exam or surgical gloves. Rings a) hold bacteria under the band, and under 
stones and in crevices which can lead to cross-contamination between the HCW and patients when the gloves leak; b) are more likely to perforate gloves when they have embedded stones, crevices, or sharp edges, making hand hygiene practices less efficient, and retain microorganisms for longer periods of time; c) make it difficult to don and remove gloves; d) decrease manual dexterity; and e) can amplify injuries to fingers while working with power equipment and can strip or cut a finger off, strangle the finger when crushed, or act as a conductor when working with electrical equipment.

Individual microbes and germs are not visible, but their colonies are. In a preliminary study by our group, a fluorescent powder, (Glo Germ $\left.{ }^{\mathrm{TM}}\right)$ glows in ultraviolet light and can be used to simulate where germs accumulate, especially in areas that are difficult to clean. A rubber human hand manikin was made and four fingers fitted with rings (stone setting, snug, loose, and tight) to determine if simulated microbes could be effectively removed. Four hand sanitation methods were used that tested the temperature of the water, duration of washing, style and tightness of rings, and the use of liquid soap. To measure the remnants of Glo Germ ${ }^{\mathrm{TM}}$, outcome measures included light meter readings of the fluorescent dye before and after washing, and digital images. The most effective treatments were washing with warm water and liquid hand soap. Washing for longer periods was more effective than short periods. The palm of the hand was cleaned more effectively than the back of the hand (Alur, Rane, Scheetz, Lorenz and Gettleman, 2009).

Several studies have found that more bacteria are retained under fingers with rings than without rings (Lowbury et al., 1968). Hoffman and colleagues conducted a 
survey in medical and surgical wards among nurses who wear rings permanently.

Samples were collected from the same hand from underneath the rings and another from the non-adjacent bare finger (control). Forty percent of the fingers with rings regularly contained gram-negative bacteria for five months with the same strains, confirming that the rings retain the same microorganisms for long periods of time (Hoffman et al., 1985).

To find if wearing rings and performing hand washing procedures changes bacterial colony counts among transient and residual microorganisms present on the surface of the hands, a study was carried out among hospital nurses delivering patient care in acute care agencies. Results showed that bacterial counts did not differ from the hands of the people wearing rings compared to those without rings after following a thorough procedure of washing the hands using hand washing agent (Jacobson, 1985).

Yildirim and colleagues conducted a study to determine the effectiveness of alcohol-based hand disinfection solutions when wearing rings, and the contamination of hands when wearing different varieties of rings. For this study, they selected 84 nurses working in intensive care units of a pediatric hospital and asked them to wear rings two weeks before starting the study and to continue wearing them until the end of the study. Cultures were obtained from the hands of the nurses wearing plain wedding rings, rings with stones, and without rings, all after washing with an alcohol-based hand disinfectant. Even after using the hand disinfectant, there was significant growth of gram- positive and gram-negative organisms; no difference between total bacterial counts were noticed on hands with plain wedding rings and rings with stones compared 
with hands without rings (Yildirim et al., 2008). This and the previous paper by Jacobson et al. are the only papers not finding that rings pose a hazard.

A study by Salisbury (1997) addressed the following questions: a) Does wearing rings increase bacterial counts on HCW's hands before washing? b) Does wearing rings decrease the effectiveness of hand washing in reducing bacterial counts on HCWs' hands? A study was conducted among $50 \mathrm{HCW}$ searing rings with another $50 \mathrm{HCWs}$ without rings. Samples are taken before and after hand washing using a timed-friction rinse, followed by culturing. Results demonstrated higher bacterial counts before hand washing and with the rings than the other group without rings.

Contamination by group A streptococci to HCWs is spread by direct person-toperson contact, mostly via droplets of saliva or nasal secretions. A more recent study tested the number of HCWs affected after exposure to a single patient with a specific group A streptococcus species. Twenty-four HCWs developed symptoms of pharyngitis within four days after exposure to the source patient (Kakis et al., 2002).

Studies have demonstrated that dental health care personnel are frequently unaware of minute tears in examination gloves resulting from clinical procedures, or caused by finger rings with stone settings and sharp edges. During operative and prosthetic procedures, there is high risk of transfer of microbes from patient to dentist due to the presence of perforations in the gloves. One study suggested that prosthodontists are in contact with oral fluids due to undetected glove perforations at least once out of 20 treatments (Nikawa et al., 1996). 
A study done among surgical intensive care unit nurses compared the effectiveness of three different types of hand hygiene agents. Results showed that repeated infection with potential nosocomial pathogens was related to the number of rings used/worn, fully 10 times more than fingers without rings. The authors noticed that an alcohol-based hand rub is more effective to reduce the bacterial count (Trick et al., 2003).

In a study of 60 intensive-care nurses, multivariable analysis determined that rings play a significant role in carrying gram-negative bacilli and Staphylococcus aureus, and the concentration of the organisms correlated well with the number of rings worn (Hayes et al., 2001). Another study demonstrated that Enterobacteriaceae accumulated around plain rings and not $S$. aureus or non-fermentative gram-negative rods (Fagernes et al., 2007).

A study done by comparing five types of nitrile gloves to two types of nonsterile latex gloves noticed fewer pre-existing defects in nitrile gloves than latex. The gloves were tested for flaws by filling with air and observing bubbles after submerging under water. Results showed that latex gloves had $0 \%$ pin-hole defects in nonpowdered surgical latex, and 3\% in powdered latex, with defects located on the thumb, middle and ring fingers. Among five types of nitrile gloves it was noticed that three had $0 \%$ defects, a fourth type had $2 \%$ located on thumb and ring finger, and the fifth type has one defect on the middle finger (Patel et al., 2003).

A study conducted among 60 periodontal and operative dentistry students and medical students wearing rings on one hand and no rings on other, compared the 
effectiveness of an alcohol-based hand sanitizer, an alcohol-chlorhexidine (scrubless) lotion, and a povidone-iodine scrub. Similar bacterial colony counts were found on the ring and non-ring hand when the students used the alcohol-based hand sanitizer, with a lower count using the alcohol-chlorhexidine lotion. With povidone-iodine, an increase in bacterial counts were found around the rings compared to the non-ring sites (Wongworawa and Jones, 2007).

Rupp and colleagues reported that nurses in two medical-surgical ICU units were allowed to use an alcohol-based hand gel to measure the adherence rate of the hand gel and contamination with nosocomial infectious agents. Acceptance of the alcohol based hand gel increased in both the units. Nurses with long fingernails (more than $2 \mathrm{~mm}$ long) and with rings on the hands accumulated more bacteria as measured by colony-forming units (CFUs). Microbial species differed between short fingernails and on fingers wearing rings when worn during patient care. The main reason for the increase in the count in these areas was thought to be limited contact with the hand gel (Rupp et al., 2008).

A survey found that HCWs accept that by wearing finger rings, artificial nails, and longer finger nails under gloves, despite hand washing, contribute to nosocomial infections. By using sterile techniques in the operating room, nosocomial infections can be reduced (Kennedy et al., 2004). Hand hygiene is equally important among laboratory personnel and other healthcare workers as found in another study, which noticed pathogenic organisms exclusively on the hands of laboratory personnel who wore finger rings, watches, or bracelets. A decrease in bacterial count was noted without jewelry (Alp et al., 2006). 
Removal of finger rings before scrubbing reduces microbial counts in areas under finger rings, compared to adjacent skin or the opposite hand. Without the effect of rings, bacterial counts decrease but remained higher than adjacent skin on the opposite hand. Kelsall et al. (2006) suggested not wearing rings before scrubbing the hands. In another study, food service workers participated in a study to determine the effect of bacteria in a simulated environment and found that the presence of rings slightly reduced the efficacy of hand washing. The most important factors leading to reduced microbial counts were using an antimicrobial agent (chlorhexidine gluconate), removal of rings, and the drying method (with paper towels rather than air drying (Montville et al., 2002).

An experiment conducted by Field et al., (1996) examined 20 dental surgeons and 20 non-clinical staff in order to measure and identify the type of bacteria obtained from four different hand sites. Samples were collected from the skin underneath rings and same site on the other hand without rings, from the skin underneath the watch face, and the wrist on the other hand (control). Bacterial counts under the rings and watches were higher than the control sites. There was not much difference noticed in microbial counts between dental surgeons and non-clinical staff, but it was thought that glove tears/perforations may spread the infection to immunocompromised patients and recommended removal of rings and watches prior to dental operative procedures.

Removal of jewelry is necessary before scrubbing the hands as shown by a study conducted among nurses wearing three different types of jewelry: finger rings, nose rings, and earrings with pierced ears, compared to no jewelry. Results revealed that less bacterial contamination was caused by the ear piercings and nose rings, which can be 
left in place as these are protected with masks and caps to reduce cross-contamination. Higher bacterial counts were observed under finger rings, which could lead to infection. There was a call for the further study to prove whether finger rings results in skin infections (Bartlett et al., 2002).

A study by Larson et al., (1989) was conducted to demonstrate the effectiveness of hand washing agents on bacterial hand flora. Four different hand washing agents ( $2 \%$ chlorhexidine gluconate, $0.6 \%$ parachorometaxylenol, $0.3 \%$ triclosan, and a non antibacterial soap control) were used at two different hand washing frequencies (six or 18 times/day) continuously for five days. There was no effect in bacterial CFUs on the hands after using the hand washing agents six times/day for 5 days. The volunteers who used the antibacterial agent for 18 times/day for 5 days, however, observed a higher reduction in the bacterial flora on the hands compared to the non antibacterial soap. Chlorhexidine gluconate proved to be more effective in reducing microbes on the hands at both low and high frequencies, compared to parachorometaxylenol and triclosan.

Two other studies also demonstrated that chlorhexidine gluconate, when used as a washing agent, has the ability to reduce bacterial counts while retaining its capacity with a residual effect. It was considered the best surgical hand scrubbing agent (Paulson et al., 1994) (Aly \& Maibach, 1988).

Tami et al. (2006) found that the majority of perforations (piercings) was found in the glove on the non-dominant hand (6/8 hands; $75 \%)$. The non-dominant hand was also the left ringed hand in the majority of the participants who punctured their gloves ( $4 / 6$ hands; $67 \%)$. Most of perforations were located at the fingertips $(7 / 11 ; 63.6 \%)$ (see 
Figure 1); only one was a tear at the tip of the thumb, which was likely created during glove removal. Eight of eleven perforations were made in the left ringed hand $(73 \%)$. 


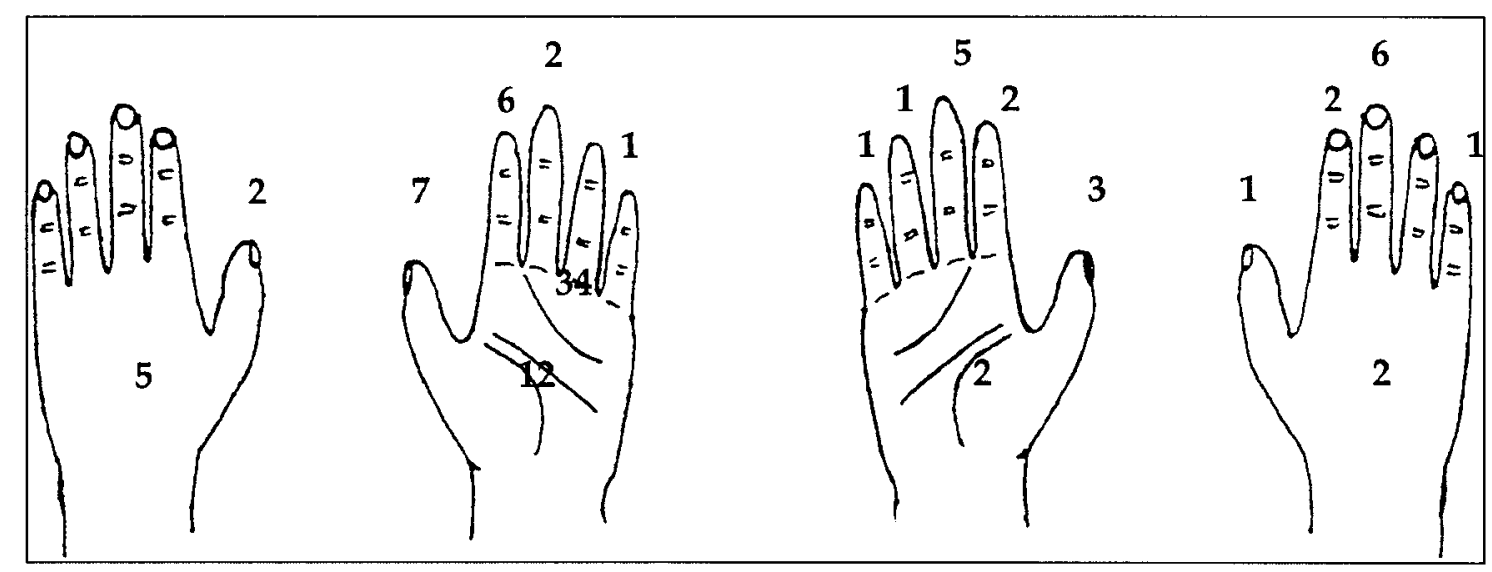

Left hand

Right hand

Figure 1: Common sites of glove perforation (from Tami et al. 2006). 
The oral streptococci are very heterogeneous with little in common other than they are streptococci and inhabit the mouth. Although they are considered commensal microbes, most are also opportunistic pathogens and have been linked with a variety of diseases, especially brain abscesses, liver abscesses and infective endocarditis (CDC, 1999).

After various studies it was found that Streptococcus mutans was the major bacterium related to early carious lesions. A medium was prepared in order to isolate Streptococcus mutans from other species of streptococcus found in the oral cavity. Out of 90 strains isolated from the oral cavity, only five strains were identified as Streptococcus mutans which induced dental caries. These strains also showed growth and resistance to sulphonamide when cultured on Direct Sensitivity Test (DST) agar plus 7\% human blank blood. Apart from S. mutans, other strains were also found to be resistant to sulphonamide. To grow only $S$. mutans, a medium was prepared that has same properties as mitis-salivarius agar to which sulphonamide is added. Maintaining a $95 \%$ nitrogen $/ 5 \%$ carbon dioxide atmosphere, samples were collected from the human oral cavity and cultured for $48 \mathrm{hr}$ at $37^{\circ} \mathrm{C}$. On this medium, colonies of $S$. mutans were formed and growth of other streptococcus organisms was reduced to less than $5 \%$, compared with ordinary Mitis Salivarius agar medium (Carlsson, 1967). 


\section{CHAPTER II}

\section{RATIONALE}

It has been observed by us that HCWs too often wear rings, with or without stones and/or sharp edges, under their gloves on one or both hands while performing dental and other medical treatment procedures on patients. The hands of HCWs with rings can play a major role in contamination and the direct spread of bacteria to their patients and vice versa.

The present study addresses the following questions: Does wearing rings with or without embedded stones, sharp edges, or openings a) increase the bacterial count on HCWs hands before washing; b) decrease the effectiveness of hand washing both before and after dental procedures in reducing bacterial counts on HCW's hands;

c) affect the effectiveness of hand washing by decreasing the bacterial counts on HCWs hands, or do the rings act as a reservoir for soap or hand sanitizer; d) affect the number and size of tears in gloves; and e) increase the bacterial count after performing dental procedures?

In addition, the following additional questions can be addressed regarding handedness: Does right or left hand dominance; f) affect contamination if rings are worn on the dominant or dependent hand; and g) affect the number or size of glove tears?

Based on these questions, a study was conducted using 50 dental students during their clinical training at the University of Louisville, School of Dentistry, with rings on the dominant and dependant hands while wearing disposable non-sterile nitrile exam 
gloves during two successive clinic sessions. The study was a randomized, controlled, single crossover clinical trial design. Microbiologic samples were taken before and after the clinical procedures, and before and after hand washing (four sample periods).

\section{HYPOTHESIS and VARIABLES}

Hypothesis: Wearing finger rings (with or without embedded stones, sharp edges, or openings) by dental health care workers (HCWs) traps and retains oral streptococci after dental clinical procedures.

Independent Variable: Finger rings (with or without stones, sharp edges, or openings) under gloves of the little or ring finger, and the middle or index finger of the right or left hands. Assignment of right and left hand was randomized.

\section{Dependent Variables:}

a) Microbial counts derived from sample swabs taken from under the rings and between the fingers (in the interphalangeal space between the little and ring finger, and the space between the middle and index finger) expressed as colony-forming units $\times 10^{5} / \mathrm{mL}$ $\left(10^{2} / \mathrm{L}\right)$

b) Number of gloves used by subjects;

c) Size of tears in the gloves (0-10 rating scale);

d) Estimate of glove leakage ( $0-10$ rating scale);

e) Gender of the subjects (male or female); 
f) Handedness of the subjects (right or left);

g) Type of dental procedure (operative, prosthodontic, periodontic, general examination, or oral surgery);

h) Duration of the dental appointment (in minutes); and

i) Use of cold or warm water during hand washing.

\section{Control Group:}

A control group was used: the interphalangeal spaces with no rings on the other hand (right or left) of each dental student. Assignment of right and left hands was randomized.

\section{Design:}

A randomized, controlled, single crossover design was chosen. 


\section{CHAPTER III}

\section{PROCEDURE}

\section{Criteria for Dental Student Subjects:}

Inclusion: Male and female junior and senior dental students who may or may not wear rings (with or without stones, sharp edges, or openings) on both hands, and who would be willing to wear two rings during two dental clinic sessions, supplied for this study.

Exclusion: 1) Inability or unwillingness to remove existing finger rings; 2) Students who wear rings on the thumb; and 3) rings that do not fit the fingers (too large or too small).

\section{Criteria for Patients:}

Inclusion: 1) Adult male and female dental patients $\geq 21$ years old; and 2) Patients in need of restorative and/or prosthetic dental procedures.

Exclusion: Patients in need of pediatric dental procedures.

Volunteer participation of dental students in either the $3^{\text {rd }}$ and/or $4^{\text {th }}$ year ULSD Class of 2010 or 2011 ( $~ 80$ students/class) performing operative and prosthetic dental procedures of at least 60 minutes' duration in a 3-hour session. Only 50 students were used. Dental students, but not patients (because none of the 18 HIPAA patient identifiers were recorded) signed an Informed Consent Document approved by the UofL 
IRB Biomedical Board (Tracking No. 09.0416, pre-approved January 29, 2010, with final approval March 26, 2010) before starting dental treatment.

The study was divided into two treatment sessions:

Session 1: Finger rings were worn on two non-adjacent fingers (excluding the thumb) of either the left or $\underline{\text { right }} \underline{\text { hand }}$ assigned randomly (experimental variable), and no finger rings worn on the right or left hand, respectively (control) (see Figure 4).

Session 2: Finger rings were worn on two non-adjacent fingers (excluding the thumb) of either the right or left hand (experimental variable), and no finger rings worn on the left or right hand, respectively (control).

These two conditions were randomly assigned (left or right hand with or without finger rings during the first session, to wear under the gloves as shown in (Figure 3), or right or left hand rings with or without finger rings during the second session) on different clinic sessions. Finger rings were provided to students who did not wear rings a few days in advance (for accommodation to the rings) (see Figure 2). 


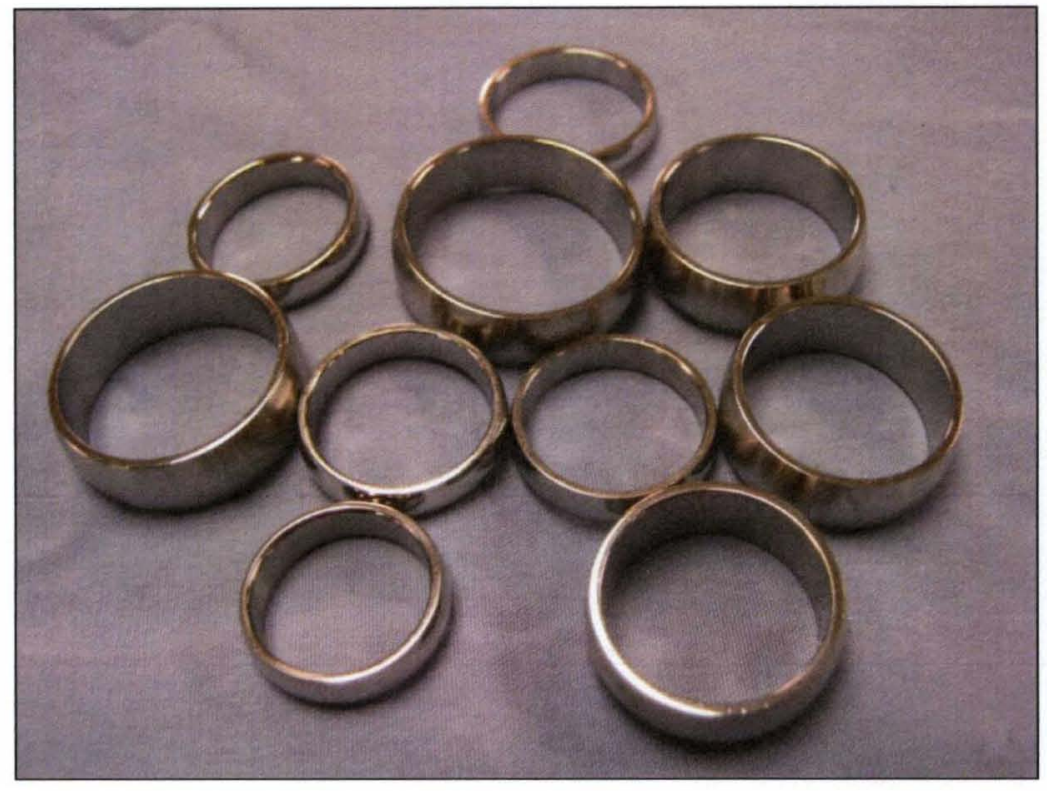

Figure 2: Men's and women's stainless steel rings of different sizes provided by the investigators.

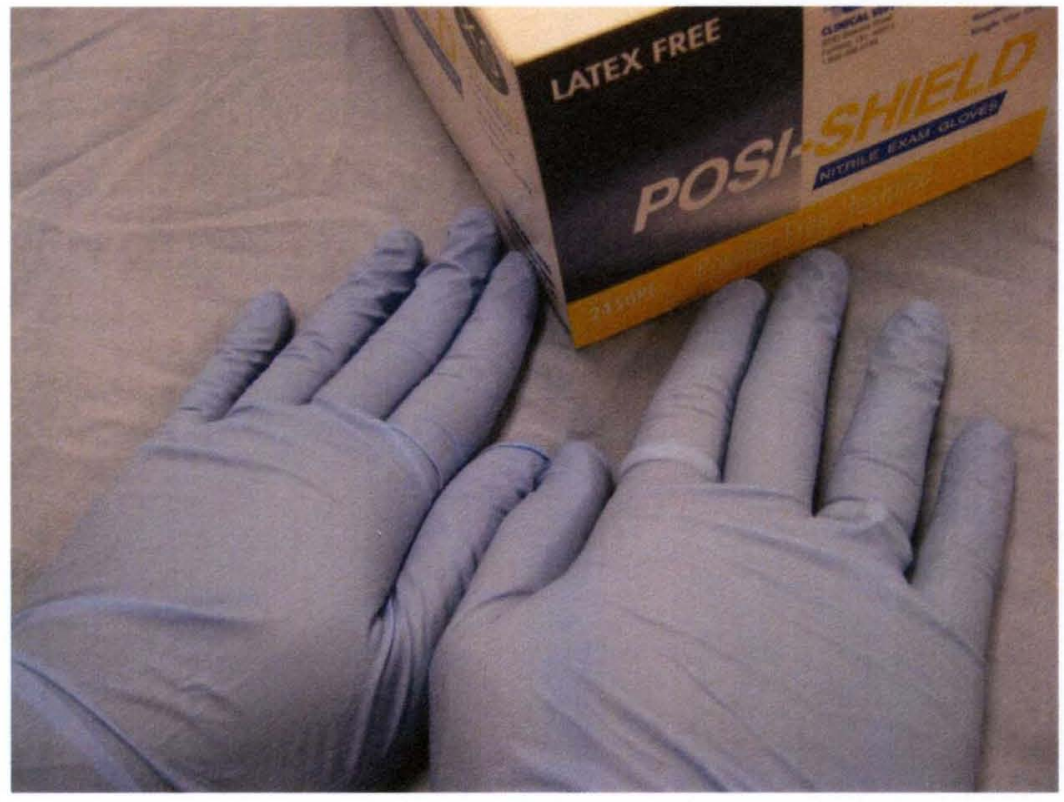

Figure $\underline{3}$ : Investigator's nitrile-gloved hands with two rings in place on index and ring fingers of right hand 


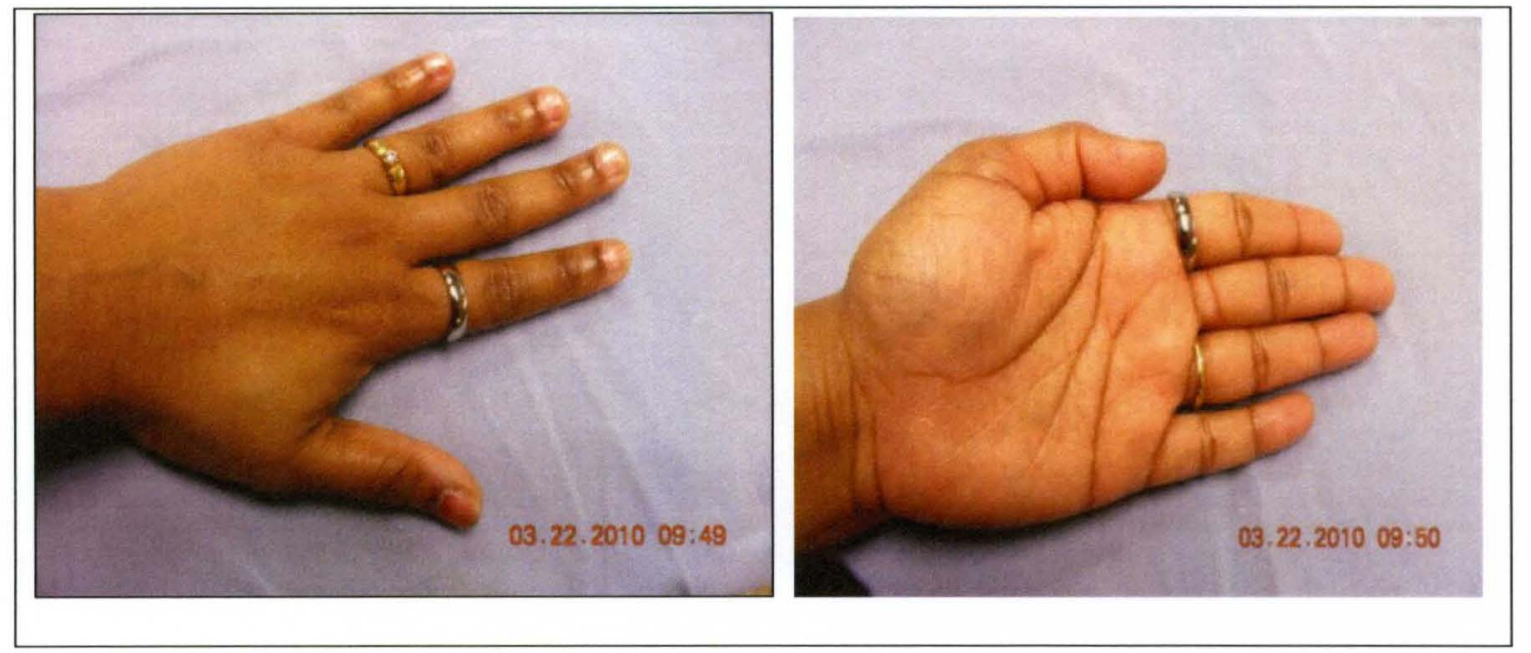

Figure 4. Left: Example of stainless steel ring on the index finger and gold ring with a stone on the ring finger of the left hand. Right: Same hand from the palmar view. 
During the dental clinical procedure, records were kept of the a) hand dominance of the dental student subjects; b) type of dental treatment(s) [CDT code(s)]; c) duration of the procedure in minutes; d) number of gloves used for left and right hands; e) Number of tears in the gloves (0-10 rating scale); f) size of glove defects using a water inflation test (0-10 rating scale); g) gender of students (male or female); and h) use of hot or cold water when washing. Dental student subjects were provided with two separate boxes to collect the right and left gloves during and after treatment.

The quantity of oral streptococci in the interphalangeal spaces under rings and on bare fingers was measured a) before washing the hands (before pre-wash); b) after washing but before donning gloves (after pre-wash); c) after finishing the dental clinical procedure with gloves removed (after procedure); and d) after a final washing of the hands (after post-wash) $[16+16=32 \times 50=1600$ microbial samples $]$. A maximum of thirty-two swabs per student per clinical session were obtained.

\section{METHODS and MATERIAL}

\section{Subjects}

Participants recruited for this study were 50 junior and senior dental students from the University of Louisville's School of Dentistry. Dental students were considered for the study if they expected to perform routine operative and prosthetic dental treatment procedures on their patients. Students were excluded from the study if they provided pediatric dental treatment to their patients, or wore rings on the thumb of one or both hands. The students signed the IRB-approved consent form; the patients were not consented as there was no identifiable information recorded. 
At least one day before the actual treatment session, the students were given two disinfected stainless steel rings sized to their fingers by the investigators to wear on either the index or middle finger, or the ring or little finger continuously on one hand. If the subjects already wore one or more rings on one hand, they were allowed to continue using those rings in the study.

\section{Microbial Sampling}

Microbiological samples were collected from the skin underneath the rings and the adjacent interphalangeal spaces between the two fingers (between the index and middle, and between the ring and little fingers) (experimental). Samples were also obtained from the same sites between two fingers of the opposite (non-ring-wearing) (control) hand (see Figures 5 and 6).

Sampling was done at four different periods of time in the clinics before and after completing dental procedures. The first samples were taken before the start of the procedure and before hand washing (before pre-wash); the second was done after washing the hands with PROVON ${ }^{\circledR} *$ antibacterial lotion soap (see Figure 7) and water

(hot or cold) (after pre-wash) before donning various sizes of Posi-Shield ${ }^{\mathrm{TM}} * *$ blue nonsterile nitrile exam gloves (as shown in Figure 3 and 9). The third samples were taken immediately after degloving after the dental treatment procedure(s) were completed (before post-wash), but before washing the hands with PROVON ${ }^{\circledR}$ antibacterial lotion soap and water (hot or cold). The last samples were taken after washing the hands (after post-wash). 
At the conclusion of each clinic session, the investigator collected the right and left hand blue nitrile gloves and tested them as follows: a) count; b) leaks as measured by filling them with water and making a personal judgment using a 1-10 rating scale as to the degree of water leaking through holes and tears in the gloves; and c) tear size using a personal rating scale from $0-10$.

Sterile microbial swabs were used for sampling. After collecting contaminants under the rings and between the fingers, the swabs were placed in test tubes containing $5 \mathrm{~mL}$ of sterile saline solution. A total of four samples was obtained at each period of time from the ring sites of one hand and from the bare skin of the other hand (16 samples per student per clinic session). Samples were taken for two clinical sessions $(16+16=32)$ for each subject. While taking the samples the investigator wore a new pair of gloves each time before collecting the samples from the students in order to reduce cross-contamination. The samples in the test tubes were immediately taken to the laboratory for further culture.

* Gojo, Inc., Akron, Ohio

** Clinical Supply Co., Fairfield, Ohio 


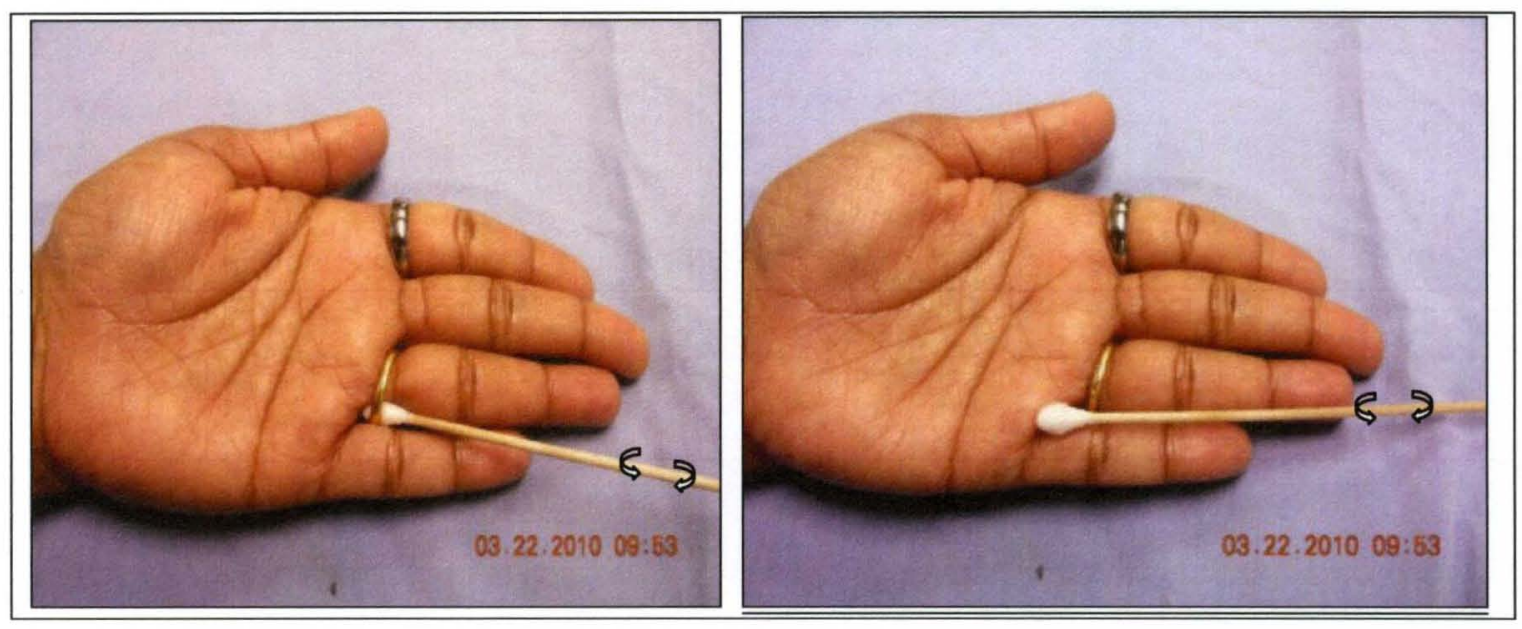

Figure $\underline{5}$. Left and Right: Sample swab used to measure the presence of microbes retained under the engagement ring and in the interphalangeal space rolled between the little and ring fingers of the left hand.

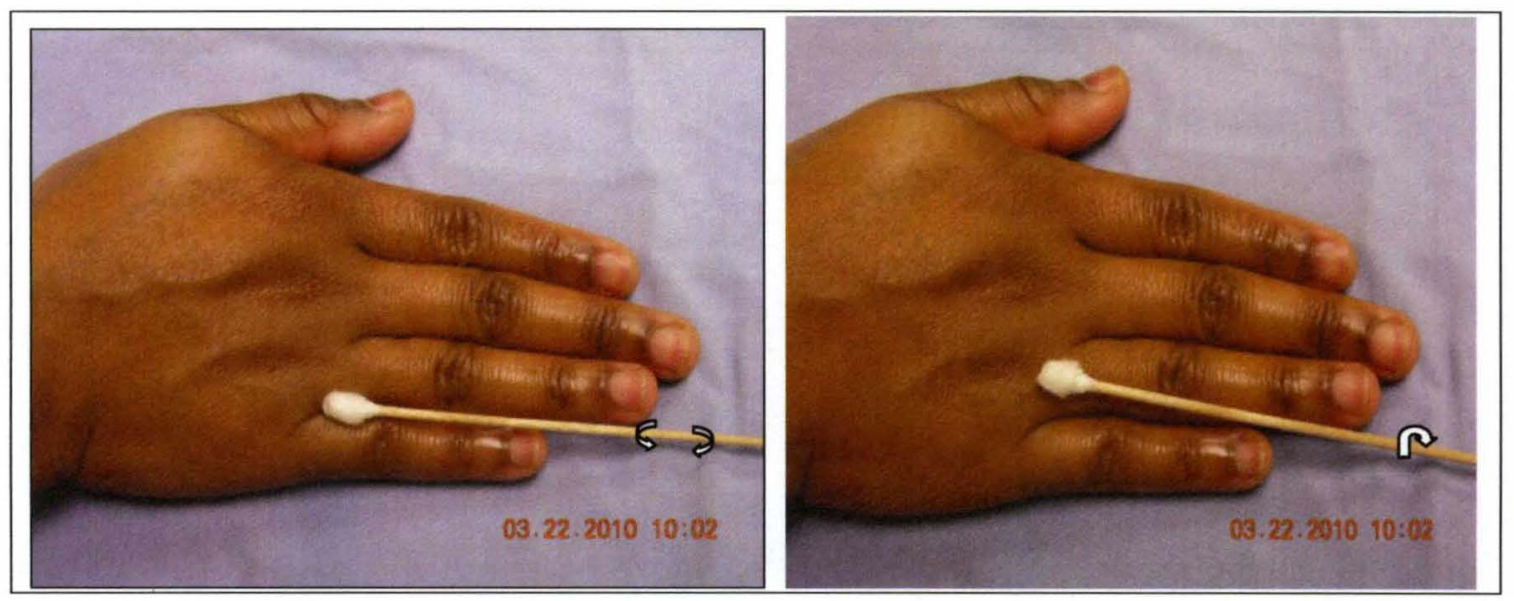

Figure $\underline{6}$. Left: Microbial sample swab in interphalangeal space rolled between little and index finger without rings.

Right: Microbial sample swab shown rolled around index finger with no ring. 


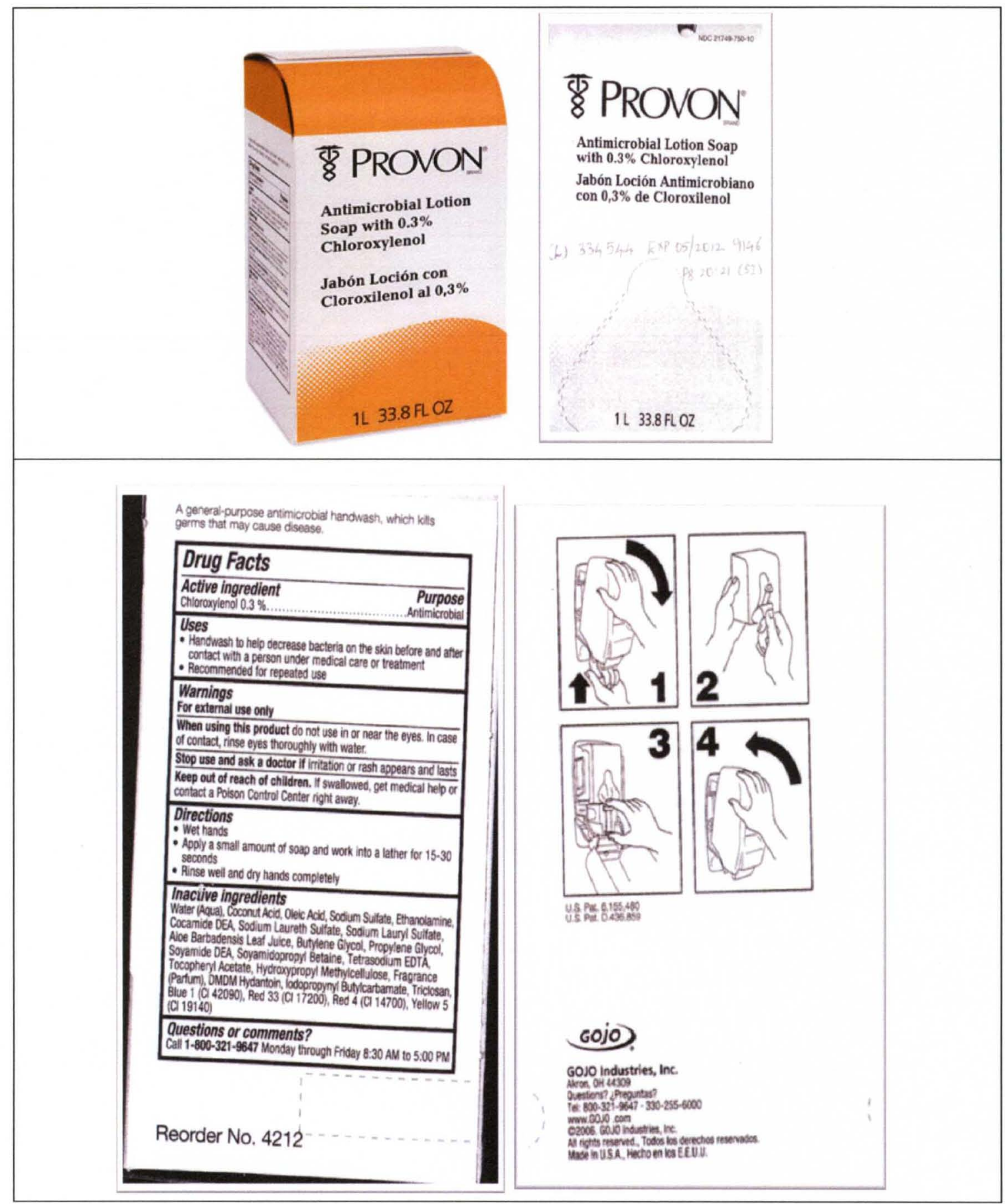

Figure 7. PROVON ${ }^{\circledR}$ Antimicrobial Lotion Soap with $0.3 \%$ Chloroxylenol. From the product literature (www.reliablepaper.com). 
“PROVON ${ }^{\circledR}$ Antimicrobial Lotion Soap contains $0.3 \%$ chloroxylenol (a broadspectrum antimicrobial agent) which adequately kills the common germs. Antimicrobial lotion effectively acts on gram-positive and gram-negative microorganisms, including methicillin-resistant Staphylococcus aureus (MRSA) and Vancomycin-resistant Enterococcus (VRE). Capable of minimizing disease-causing bacteria which leads to contamination and acquire infections. It contains mild skin cleansers, emollients, and conditioners including aloe and vitamins A \& E. More commonly used in hospitals, physicians' offices and home health agencies and famous brand in United States."

"Properties of chloroxylenol: also known as parachlorometaxylemol (PCMX), more commonly used as a preservative in cosmetics and antimicrobial soaps due to presence of halogen-substituted phenolic compound. Larson \& Talbot (1986). It acts as an antimicrobial activity of PCMX is the inactivation of bacterial enzymes and alteration of cell walls. It has good in vitro activity against gram-positive organisms and fair activity against gram-negative bacteria, mycobacteria and certain viruses. Shows less action against P.aeruginosa and acts more effectively on pseudomonas spp due to the presence of ethylene-diaminetetraacetic acid that increases its activity." Larson (1988). 


\section{MICROBIOLOGICAL METHODS}

Difco $^{\text {IM }}$ Mitis Salivarius Agar Powder* + Tellurite Solution 1\%** was used The combination of media isolates Streptococcus mutans, S.salivarius, S. mitis, and other species of oral streptococci from contaminated specimens collected from dental students before and after the clinical dental procedures. Most common normal flora present in the human oral cavity are different species of streptococci like S.mutans, S.mitis, and S.salivarius. They are considered opportunistic pathogens causing disease in the immune compromised system. Oral streptococci play an important role in cariogenesis and infective endocarditis (www.bd.com).

Peptones are the main ingredient present in Mitis Salivarius agar. The main ingredient that inhibits gram-negative bacilli and gram-positive bacteria, except for streptococci, are potassium tellurite and crystal violet. Streptococcal colonies appear blue in color due to presence of trypan blue. Ninety g of powder was mixed with $1 \mathrm{~L}$ of purified water (see Figure 8) and autoclaved at $121^{\circ} \mathrm{C}$ for 15 minutes. After cooling to $50-55^{\circ} \mathrm{C}, 1 \mathrm{~mL}$ of $1 \%$ potassium tellurite solution (see Figure 9) was added using a sterile pipette and mixed. The solution was poured into quadrant Petri dishes (VWR quadrant sterile dishes, No. 25384) using a sterile pippeting device (see Figure 10). A total of 400 dishes were used for 1600 samples.

* Difco ${ }^{\text {IM }}$ No. 229810, Difco Laboratories, Inc., BD Diagnostic Systems, Detroit, MI

** BBL ${ }^{\mathrm{TM}}$ Tellurite Solution 1\%, No. 211917, Difco Laboratories, Inc., BD Diagnostic Systems, Detroit, MI 
After the samples were collected using cotton swabs, they were placed in sterile test tubes containing $5 \mathrm{~mL}$ of $0.9 \%$ saline solution, and carried to the laboratory for further culture. Each test tube with swabs was placed in a vortex mixer for 10 seconds (see Figure 11) to allow the oral bacteria present on the cotton swabs to detach in the solution. Using a sterile pipette, $50 \mu \mathrm{L}$ of solution was placed into one of the labeled quadrants of the Petri dish (see Figures 12 and 13) and the liquid spread evenly on the medium, using a glass rod that had been dipped in alcohol.

The dishes were incubated aerobically at $37^{\circ} \mathrm{C}$ for 48 hours, whereupon the dishes were stored at room temperature until counts were made within three days. Growth of streptococci in the 400 quadrant dishes (1600 samples) (see Figure 14) was measured visually with a hand counter when needed at $60 \mathrm{X}$ in a binocular microscope using oblique and transverse illumination. If there was doubt observing the colonies, higher optical power was employed (120X, 250X). A labeling scheme was devised for the dishes (see Figure 15). Different types of oral streptococci (chains/pairs) were observed (see Figure 16). The number of colony-forming-units (CFUs) of oral streptococci was counted by two readers ( $\mathrm{SN}$ and LG) and counted with a hand counter (see Figure 17) and recorded in the data book. 


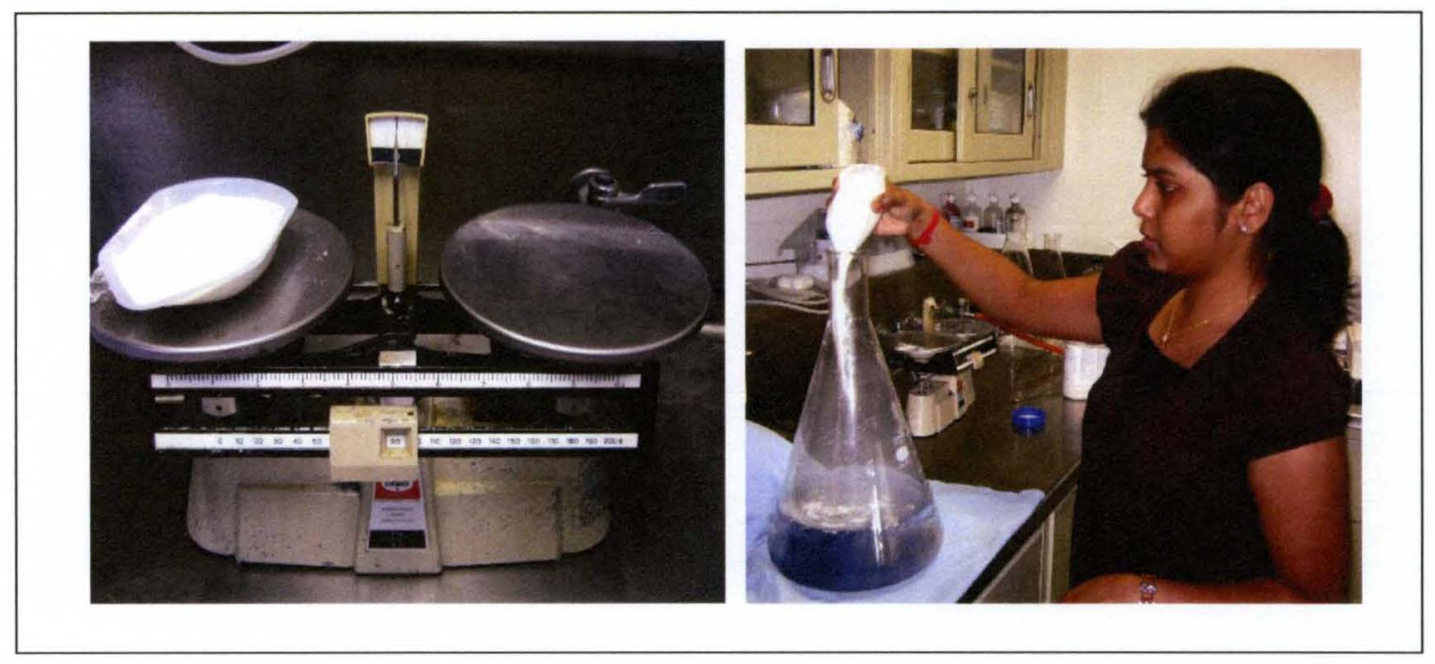

Figure $\underline{8}$. Measuring $90 \mathrm{~g}$ of Mitis Salivarius agar powder and adding it to $1 \mathrm{~L}$ of distilled water.

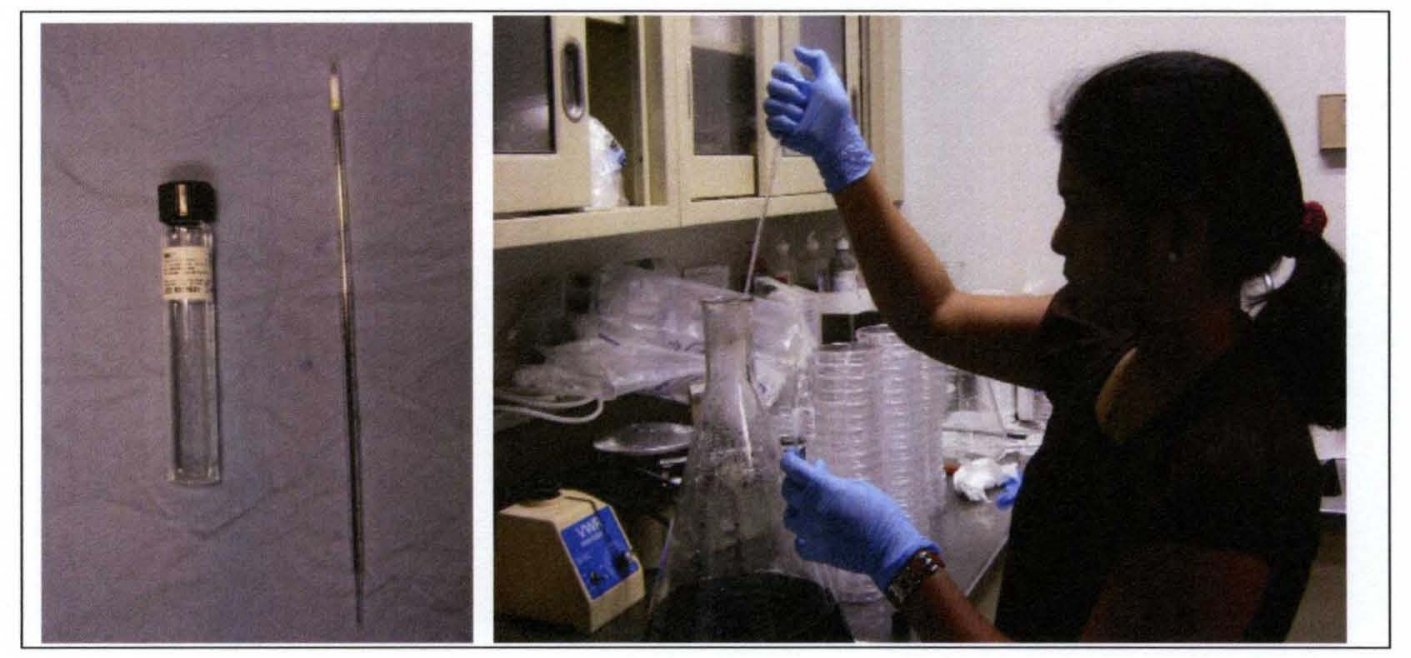

Figure 9. $1 \%$ Potassium tellurite pipetted into sterile medium. 


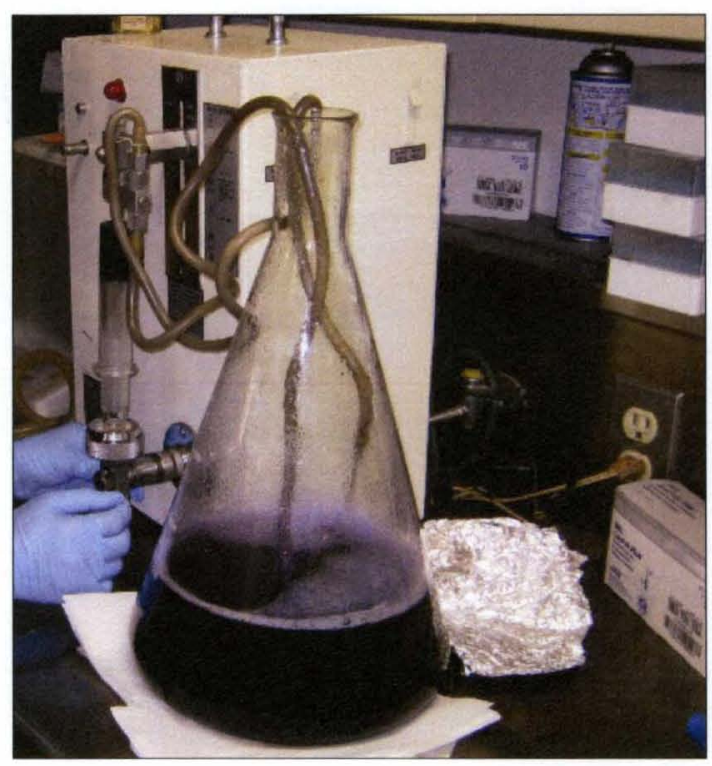

Figure 10. Sterile pipetting device to control the quantity of the medium as it is poured into quadrant Petri dishes.

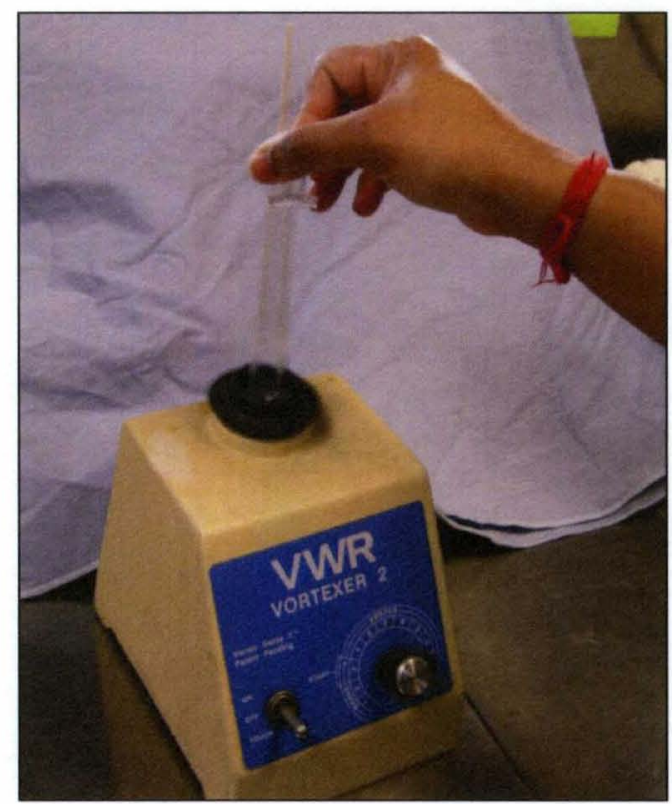

$\underline{\text { Figure } 11 .}$. Test tubes placed on vortex mixer for 10 seconds to detach oral Streptococci from cotton swabs. 


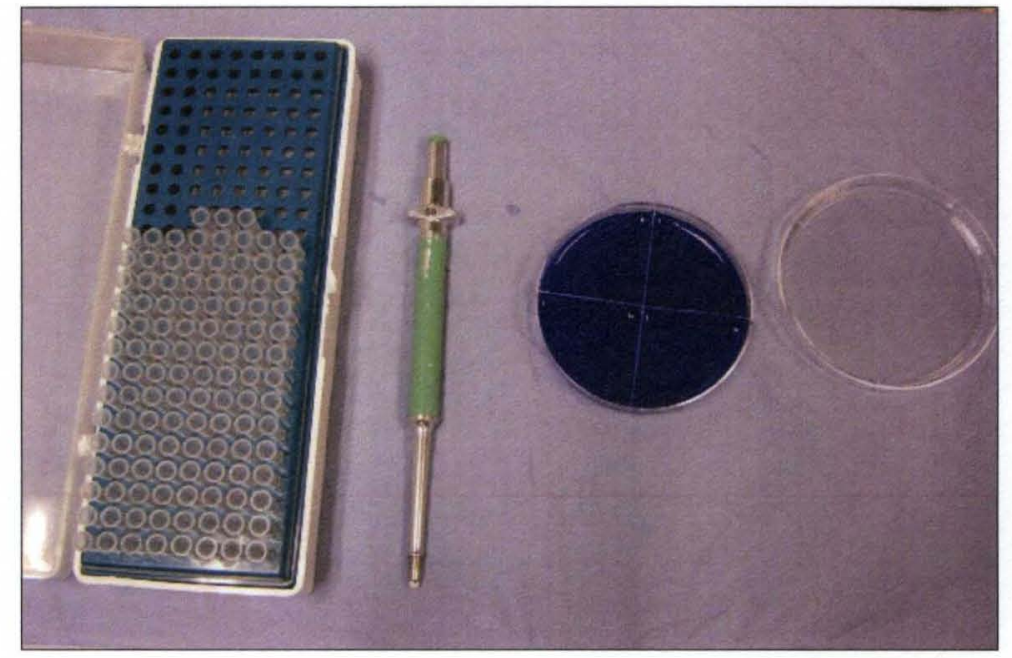

$\underline{\text { Figure } 12}$. Sterile pipette tips (left), $50 \mu \mathrm{L}$ pipettor, and quadrant Petri dishes with Mitis Salivarius agar medium (right).

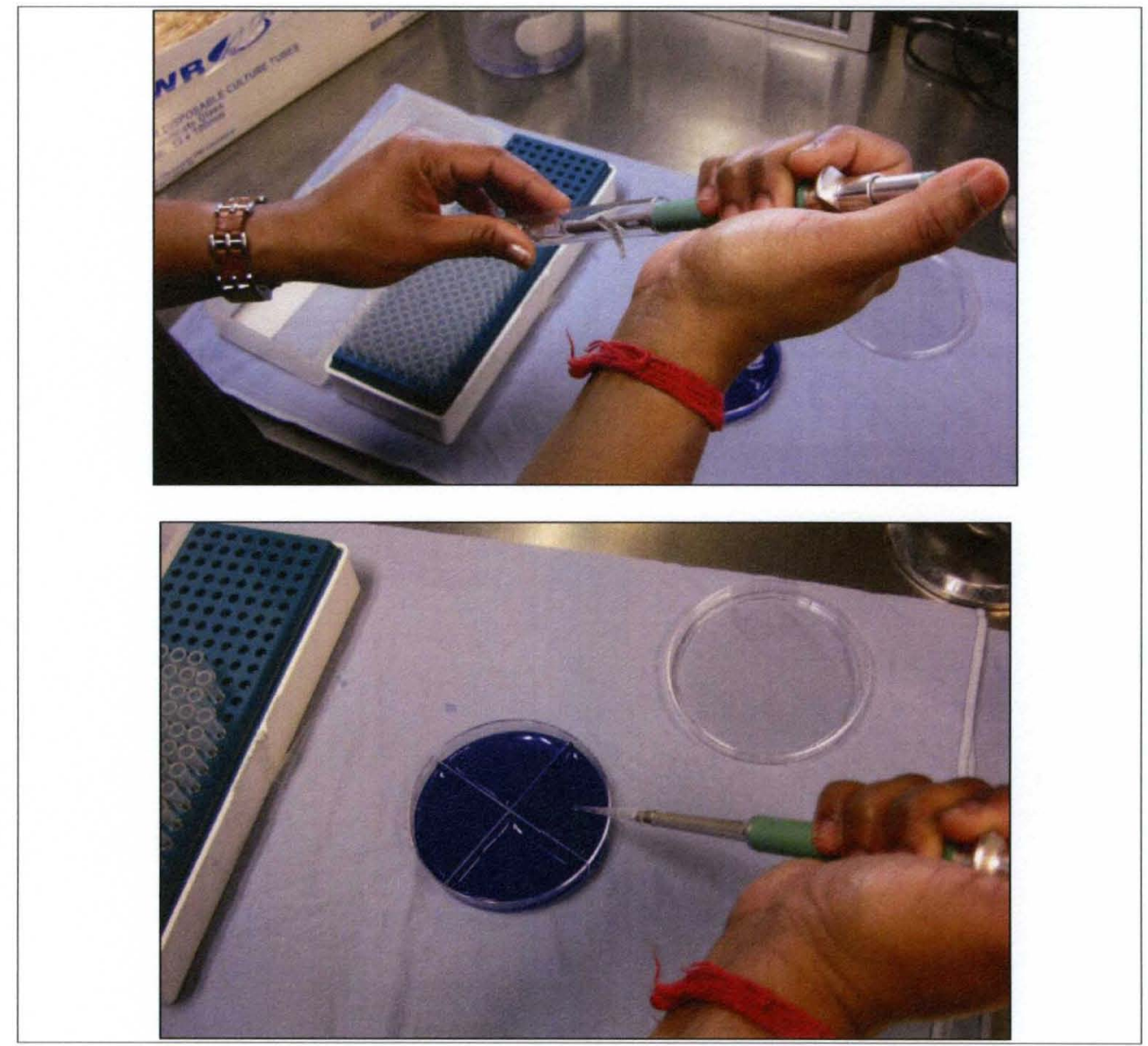

Figure 13. Delivering aliquot into quadrant Petri dishes with $50 \mu \mathrm{L}$ pipettor. 


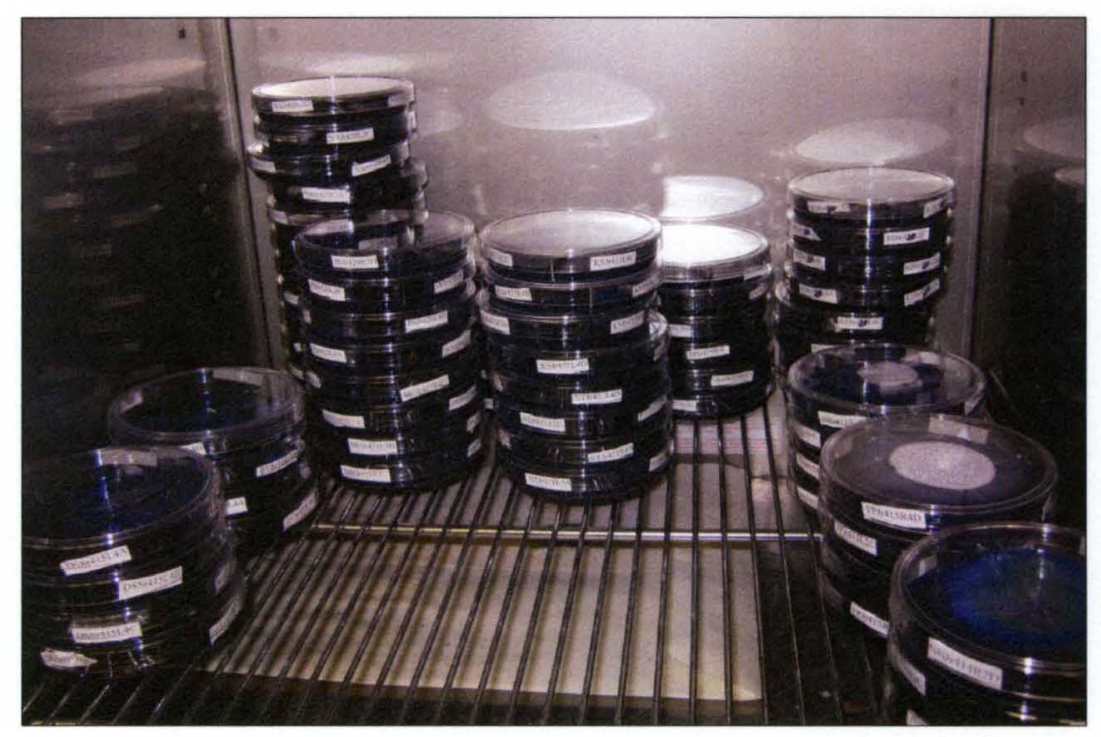

$\underline{\text { Figure } 14}$. Covered Petri dishes in $37^{\circ} \mathrm{C}$ incubator for 48 hours in aerobic conditions.

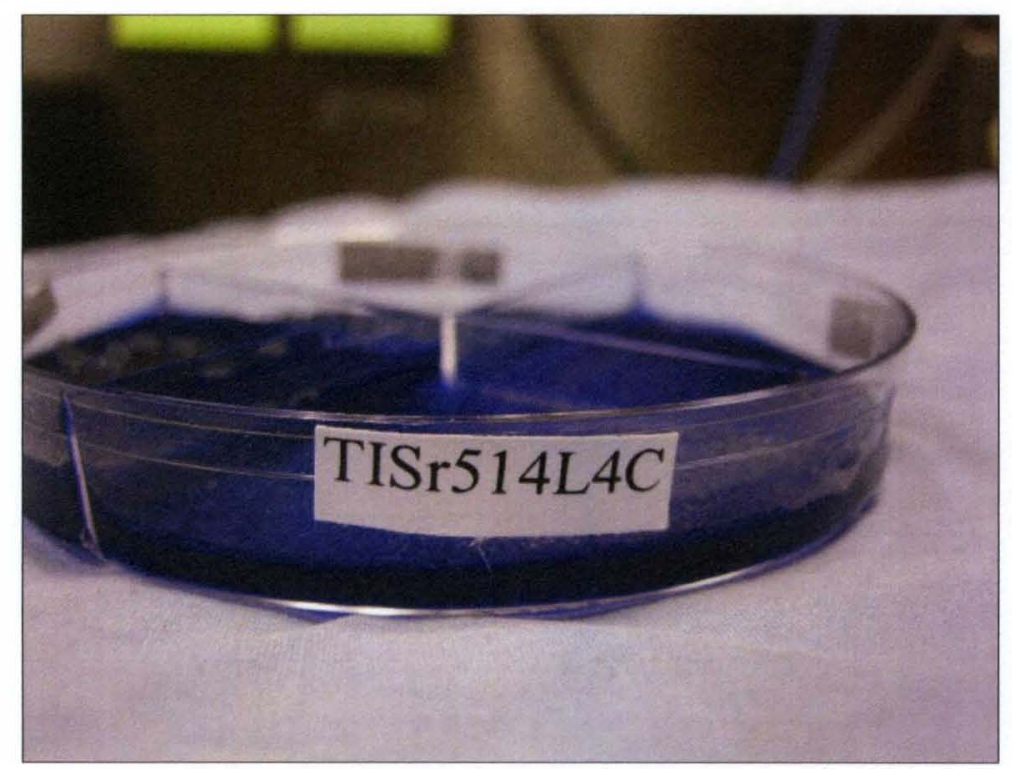

Figure 15. Labeling the quadrant dishes: TISr514L4C: TI $\equiv$ subject's initials; $\mathrm{Sr} \equiv$ dental student is a senior; 514 = month \& day, e.g., May $14^{\text {th }}, \mathrm{L} \equiv$ left hand; $4 \equiv$ interphalangeal space between ring finger and little finger; and $\mathrm{C} \equiv 3^{\text {rd }}$ time period (after dental procedure, pre-wash). 


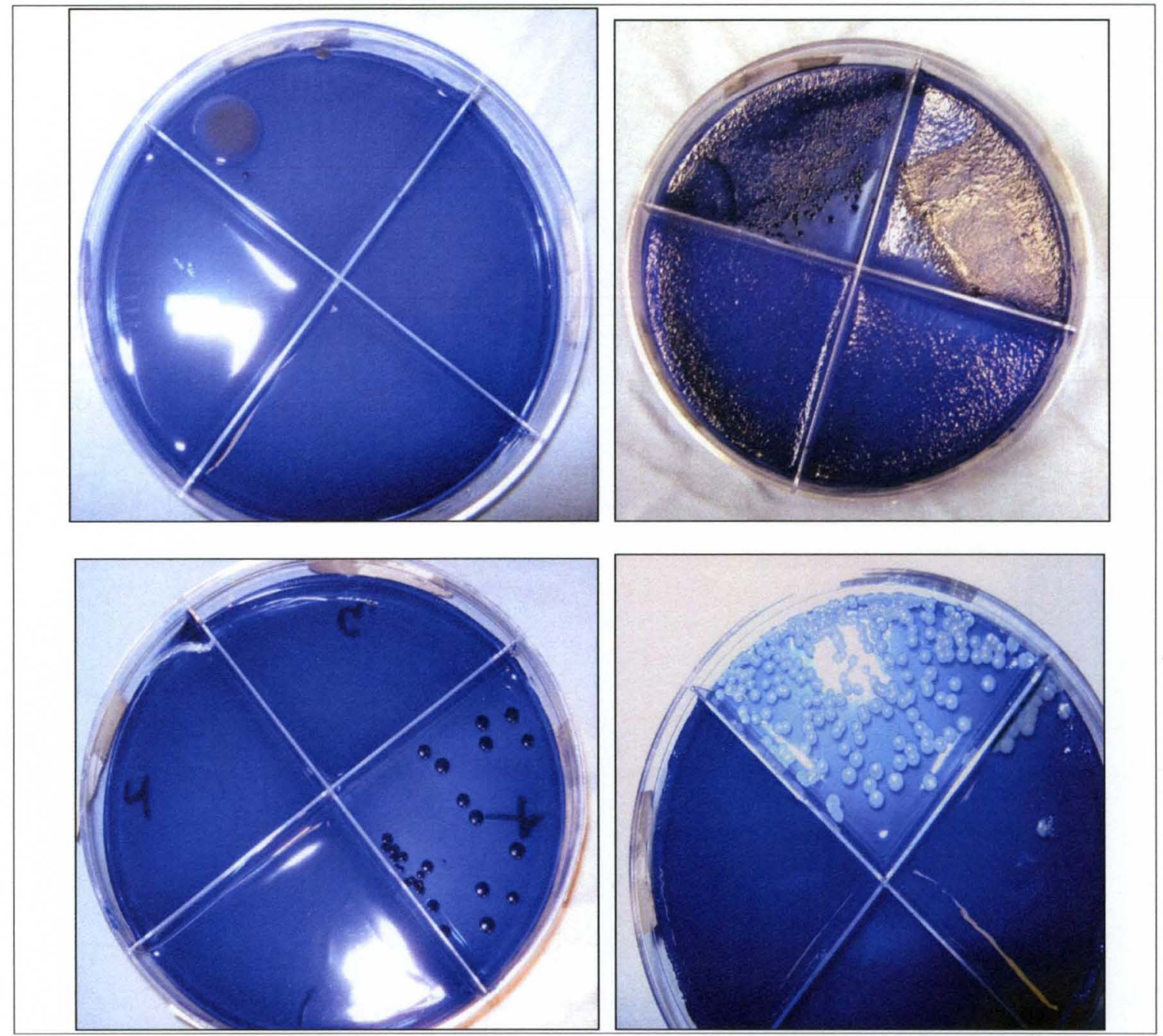

Figure 16. Quadrant Petri dishes with Mitis Salivarius agar + potassium tellurite to select for oral streptococcus after 48 -hour aerobic incubation at $37^{\circ} \mathrm{C}$. Top left: only one quadrant with a count of 3 colonies. Top right: confluence of microbial growth on top two quadrants, none on the bottom two quadrants. Lower left: only one quadrant with count of $27 \mathrm{CFUs}$; and Lower right: top quadrant $=232 \mathrm{CFUs}$, right quadrant $=$ 25 CFUs. 


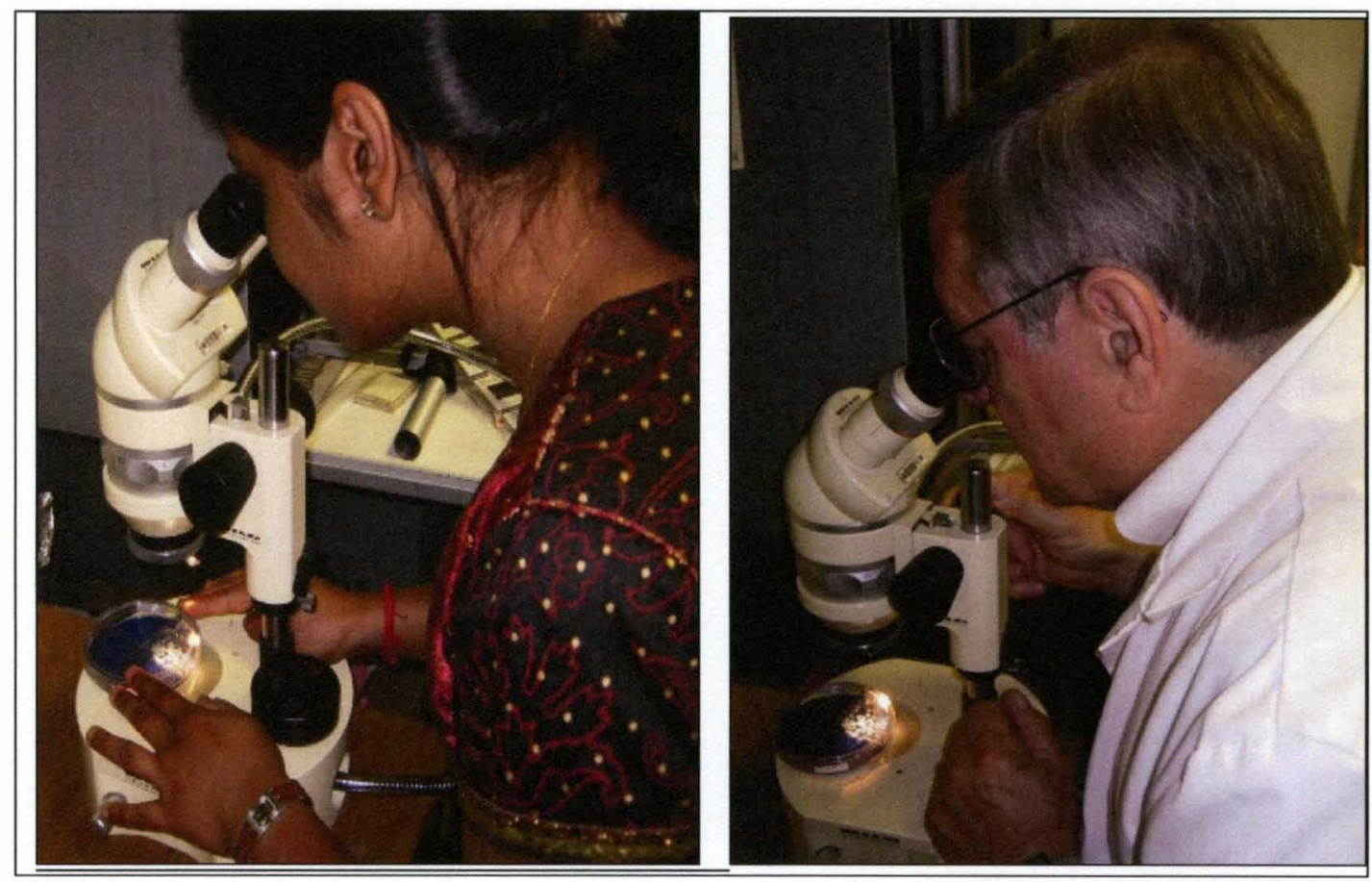

Figure 17. Counting oral streptococci spp. by Swapna Nadikuda (left) and Lawrence Gettleman (right) at $60 \mathrm{X}$ in a binocular microscope, illuminated with oblique and transmitted light. 


\section{RESULTS}

Of the fifty students who signed consent forms (see Appendix A), all completed their clinical treatment of patients in a three-hour clinic sessions and filled out the questionnaire (see Appendix B), averaging 129 minutes ( $S D=44.5$ minutes). A summary of data collected from the dental student subjects, except for the CFU counts, is presented in Table 1. A total of 206 hours of clinic time was recorded in this clinical

trial. The gender split was 24 males to 26 females, which reflects the general makeup of the ULSD classes of 2010 and 2011. Two students did not return the questionnaires. Hand dominance was 40 right handed and 8 left handed (20\%). Total glove usage was 368 right-hand gloves $($ mean $=3.97, \mathrm{SD}=1.99)$ and 367 left-hand gloves $($ mean $=3.95$, $\mathrm{SD}=1.99)$. A total of 294 right gloves were torn or had pre-existing holes $(79.8 \%)$ and a total of 259 left gloves were torn or had pre-existing holes (70.5\%). A total of 296 right gloves had leaks (80.4\%) and a total of 263 left gloves had leaks (71.6\%).

Seventy-four students reported using cold water when they washed their hands, whereas 22 reported using hot water. 


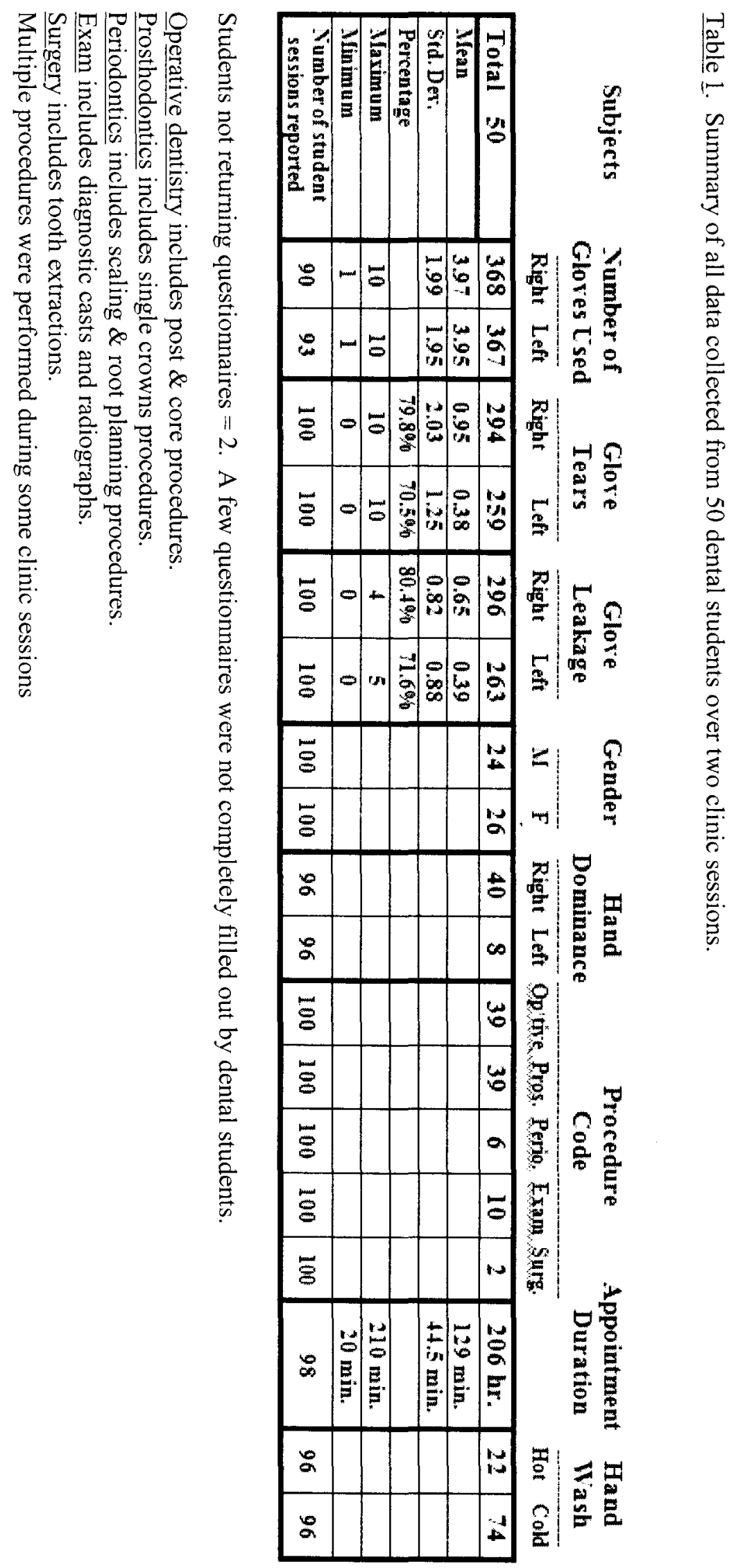


There were two defining characteristic of the bacterial count data, which complicated direct analysis of the bacterial counts. The first was the "zero-inflation" of the data, i.e., $73 \%$ of the 1600 samples (1168 samples) grew no oral streptococci (had counts of zero). While there are methods for analyzing zero-inflated count data such as these, generalizations to a repeated measures setting are more difficult. The second complicating factor is the heavy right skewness. Twelve observations exhibited counts in excess of 1000. This has the effect of eliminating mean-based inference as a reasonable method for analyzing the data. For example, although $73 \%$ of the samples had no bacteria, the average bacterial count for all the data was 25.3 ; conversely, the median was zero. Hence, traditional methods based upon means (or even medians) will likely perform poorly with these data, and are poor measures of central tendency.

Therefore, there was no direct analysis of the counts themselves. Rather, the outcome was a derived variable - whether or not a sample was contaminated with bacteria, i.e., count $>0$ ) (see Figure 18). The analysis of this outcome was a binomiallinked generalized linear mixed model, including time point, experimental condition, and hand as factors. This has the effect of greatly simplifying the analysis and resulting conclusions, which are in terms of the likelihood of contamination rather than the "size" of the contamination itself. It also may dilute potentially valuable information about the colony counts, but given the issues of zero-inflation and heavy skewness above, it would be very difficult to derive reasonable conclusions about these outcomes themselves. 


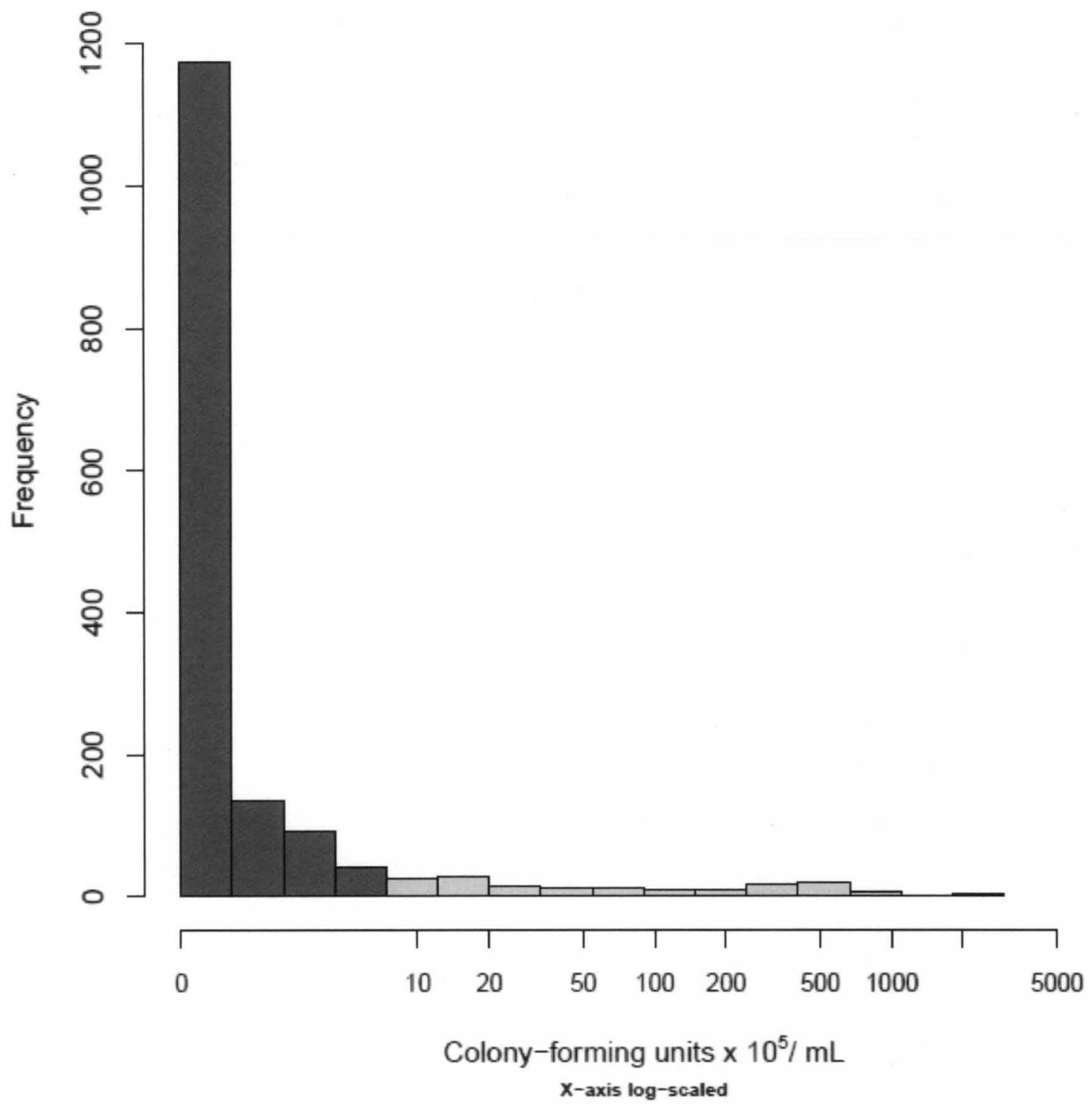

Figure 18: Dichotomous nature of the dataset. Due to zero-inflation and heavy right skewness, a cutoff of 9.0 CFUs was considered to be essentially zero readings (dark gray bars). The counts of 10 and above (light gray bars) were considered to be positive measures of oral contamination in this study. $\mathrm{n}=1600$. 
$\underline{\text { Table }} \underline{2}$ Values in table are $\%$ of samples contaminated with Streptococcus spp. with values $\geq 0$.

\begin{tabular}{|c|c|c|c|c|c|c|c|c|c|}
\hline \multirow{2}{*}{ Time } & \multicolumn{3}{|c|}{ Dependent hand } & \multicolumn{3}{|c|}{ Dominant hand } & \multicolumn{3}{|c|}{ Overall } \\
\hline & $\begin{array}{l}\text { No } \\
\text { rings }\end{array}$ & Rings & Overall & $\begin{array}{c}\text { No } \\
\text { Rings }\end{array}$ & Rings & Overall & $\begin{array}{c}\text { No } \\
\text { Rings }\end{array}$ & Rings & Overall \\
\hline $\begin{array}{c}\text { Before } \\
\text { pre-wash }\end{array}$ & $22 \%$ & $29 \%$ & $26 \%$ & $31 \%$ & $30 \%$ & $31 \%$ & $27 \%$ & $30 \%$ & $28 \%$ \\
\hline $\begin{array}{c}\text { After pre- } \\
\text { wash }\end{array}$ & $35 \%$ & $36 \%$ & $36 \%$ & $24 \%$ & $27 \%$ & $26 \%$ & $30 \%$ & $32 \%$ & $31 \%$ \\
\hline $\begin{array}{c}\text { After } \\
\text { procedure }\end{array}$ & $21 \%$ & $26 \%$ & $23 \%$ & $29 \%$ & $22 \%$ & $26 \%$ & $25 \%$ & $24 \%$ & $24 \%$ \\
\hline $\begin{array}{l}\text { After } \\
\text { post- } \\
\text { wash }\end{array}$ & $23 \%$ & $38 \%$ & $30 \%$ & $16 \%$ & $21 \%$ & $18 \%$ & $19 \%$ & $29 \%$ & $24 \%$ \\
\hline Overall & $25 \%$ & $32 \%$ & $29 \%$ & $25 \%$ & $25 \%$ & $25 \%$ & $25 \%$ & $29 \%$ & $27 \%$ \\
\hline
\end{tabular}




\section{Analysis of Contamination - Contamination Defined as $>0$ Count}

Because there were three factors to consider, the table is fairly complex, and has many margins. It is color-coded to aid with interpretation (see Table 2). The figure on the following page plots the three-way classifications (see Figure 19).

Overall percentage for all samples

In white $-27 \%$ of all samples were contaminated.

1-way classifications

In red (hand - dominant/dependent), blue (experimental condition - rings/no rings), and yellow (time point)

2-way classifications are color coded as the mixture of the 1-way colorings

Hand*Experimental Condition - in purple (red for dominant/dependent and blue for rings/no rings)

Hand*Time Point - in orange (red for dominant/dependent and yellow for time point)

Experimental Conditions*Time Point - in green (blue for rings/no rings and yellow for time point)

3-way classifications are in gray 


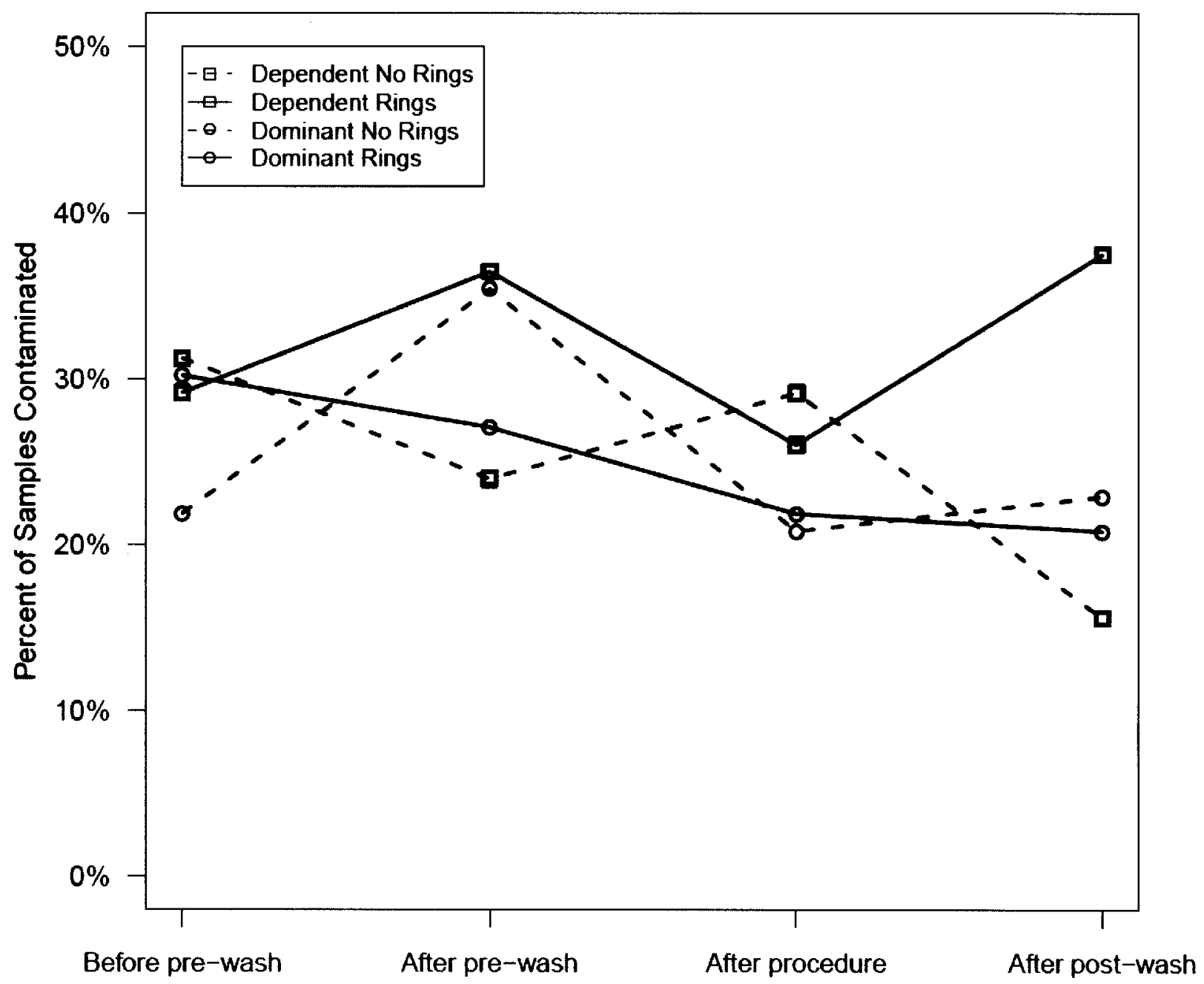

Figure 19. Raw data plot in percent of samples contaminated for all data for dominant hand and dependant hand, with and without finger rings. This displays the relative changes for the dominant and dependent hands 


\section{Hypothesis Testing:}

Overall (note that all comparisons were close to significant)

Ringed (29\%) and non-ringed (25\%) hands did not significantly differ $(\mathrm{p}=0.08)$

Dominant $(25 \%)$ and dependent $(29 \%)$ hands did not significantly differ $(\mathrm{p}=0.07)$

Time points $(28 \%, 31 \%, 24 \%, 24 \%)$ did not significantly differ $(\mathrm{p}=0.06)$

At each time point

Before pre-wash

Dominant (31\%) and dependent $(26 \%)$ did not significantly differ $(\mathrm{p}=0.20)$

Rings (27\%) and no rings (30\%) did not significantly differ $(\mathrm{p}=0.42)$

After pre-wash

Dominant hand was significantly less likely to be contaminated $(26 \%$ vs. $36 \%, \mathrm{p}=$ $0.01)$

Rings (32\%) and no rings (30\%) did not significantly differ $(\mathrm{p}=0.59)$

After procedure

Dominant $(26 \%)$ and dependent $(23 \%)$ did not significantly differ $(\mathrm{p}=0.61)$

Rings (24\%) and no rings (25\%) did not significantly differ $(\mathrm{p}=0.82)$

After post-wash

Dominant hand was significantly less likely to be contaminated (18\% vs. $30 \%$, $\mathrm{p}=0.004)$

Rings hand was significantly more likely to be contaminated $(30 \%$ vs. $19 \%, \mathrm{p}=0.02)$

Interaction of Hand and Rings

In the dependent hand, the ring (32\%) and non-ring (25\%) hands did not significantly $\operatorname{differ}(\mathrm{p}=0.08)$ 
In the dominant hand, the ring (25\%) and non-ring (25\%) hands did not significantly $\operatorname{differ}(\mathrm{p}=0.83)$

With no rings, the dominant (25\%) and dependent $(25 \%)$ hands did not significantly $\operatorname{differ}(\mathrm{p}=0.82)$

With rings, the dominant (25\%) and dependent (32\%) hands did not significantly $\operatorname{differ}(\mathrm{p}=0.08)$

In large part, none of the conducted hypothesis tests revealed anything of significance. The one result of significance with respect to the main study hypothesis comparing hands with and without rings was the comparison after the post-procedure hand washing, in which the ringed hand was more likely to be contaminated than the non-ringed hand. There were significant comparisons between the dominant and dependent hands after the pre-procedure hand washing and after the post-procedure washing. Otherwise, there was little of actual significance to report. Even significant results were not clinically substantial, i.e., differences in percentages were not great.

\section{Analysis of Contamination - Contamination Defined as $\geq 10$ Count}

Values in the table are percentage of samples contaminated with bacteria. A plot on the following page depicts these percentages (see Figure 20). The table is color coded as before (see Table 3). 
Table $\underline{3}$ Values in table are $\%$ of samples contaminated with Streptococcus spp. with values $\geq 10$.

\begin{tabular}{|c|cc|c|cc|c|cc|c|}
\hline \multirow{2}{*}{ Time } & \multicolumn{3}{|c|}{ Dependent } & \multicolumn{3}{c|}{ Dominant } & \multicolumn{3}{c|}{ Overall } \\
\cline { 2 - 9 } & $\begin{array}{c}\text { No } \\
\text { Rings }\end{array}$ & Rings & Overall & $\begin{array}{c}\text { No } \\
\text { Rings }\end{array}$ & Rings & Overall & $\begin{array}{c}\text { No } \\
\text { Rings }\end{array}$ & Rings & Overall \\
\hline $\begin{array}{c}\text { Before } \\
\text { pre-wash }\end{array}$ & $7 \%$ & $16 \%$ & $11 \%$ & $16 \%$ & $15 \%$ & $15 \%$ & $11 \%$ & $15 \%$ & $\mathbf{1 3 \%}$ \\
$\begin{array}{c}\text { After pre- } \\
\text { wash }\end{array}$ & $10 \%$ & $11 \%$ & $11 \%$ & $6 \%$ & $9 \%$ & $8 \%$ & $8 \%$ & $10 \%$ & $\mathbf{9 \%}$ \\
$\begin{array}{c}\text { After } \\
\text { procedure }\end{array}$ & $7 \%$ & $9 \%$ & $8 \%$ & $13 \%$ & $7 \%$ & $10 \%$ & $10 \%$ & $8 \%$ & $\mathbf{9 \%}$ \\
$\begin{array}{c}\text { After } \\
\text { post- } \\
\text { wash }\end{array}$ & $4 \%$ & $8 \%$ & $6 \%$ & $4 \%$ & $6 \%$ & $5 \%$ & $4 \%$ & $7 \%$ & $\mathbf{6 \%}$ \\
\hline $\begin{array}{c}\text { Overall } \\
\text { Ong }\end{array}$ & $\mathbf{7 \%}$ & $\mathbf{1 1 \%}$ & $9 \%$ & $\mathbf{1 0 \%}$ & $\mathbf{9 \%}$ & $\mathbf{1 0} \%$ & $\mathbf{8} \%$ & $\mathbf{1 0 \%}$ & $\mathbf{9 \%}$ \\
\hline
\end{tabular}




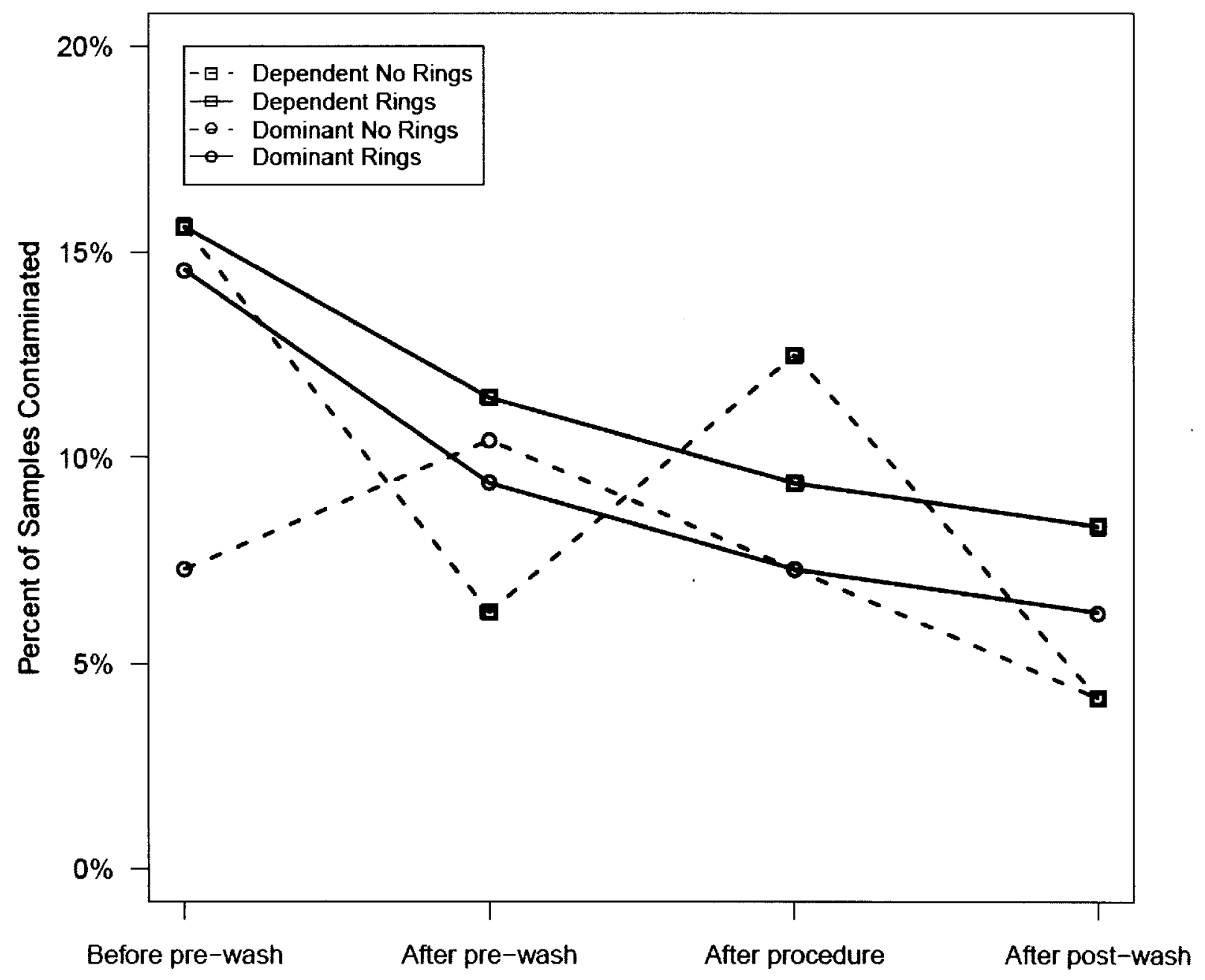

Figure 20. Raw data plot of all samples for dominant hand and dependant hand, with and without finger rings, with values $\geq 10$. 


\section{Hypothesis Testing:}

Overall

Ringed (10\%) and non-ringed (8\%) hands significantly differed $(p=0.04)$

Dominant $(10 \%)$ and dependent $(9 \%)$ hands did not significantly differ $(\mathrm{p}=0.96)$

Time points $(13 \%, 9 \%, 9 \%, 6 \%)$ significantly differed $(\mathrm{p}<0.0001)$

At each time point

Before pre-wash

Dominant $(15 \%)$ and dependent $(11 \%)$ did not significantly differ $(p=0.08)$

Rings (15\%) and no rings (11\%) did not significantly differ $(\mathrm{p}=0.08)$

After pre-wash

Dominant $(8 \%)$ and dependent $(11 \%)$ did not significantly differ $(\mathrm{p}=0.12)$

Rings (10\%) and no rings $(8 \%)$ did not significantly differ $(\mathrm{p}=0.29)$

After procedure

Dominant $(10 \%)$ and dependent $(8 \%)$ did not significantly differ $(\mathrm{p}=0.52)$

Rings ( $8 \%)$ and no rings $(10 \%)$ did not significantly differ $(\mathrm{p}=0.52)$

After post-wash

Dominant (5\%) and dependent $(6 \%)$ did not significantly differ $(\mathrm{p}=0.63)$

Rings (7\%) and no rings (4\%) did not significantly differ $(\mathrm{p}=0.08)$

Interaction of Hand and Rings

In the dependent hand, the ring (11\%) and non-ring (7\%) hands did not

significantly differ $(\mathrm{p}=0.09)$ 
In the dominant hand, the ring (9\%) and non-ring (10\%) hands did not significantly differ $(\mathrm{p}=0.97)$

With no rings, the dominant (10\%) and dependent (7\%) hands did not significantly differ $(\mathrm{p}=0.40)$

With rings, the dominant (9\%) and dependent (11\%) hands did not significantly differ $(\mathrm{p}=0.40)$

The only significant results were two of the overall tests - of ringed vs. nonringed hands $(\mathrm{p}=0.04)$ and the omnibus test of the time points $(\mathrm{p}<0.0001)$. While the time points seemed notably different (empirically and statistically), the experimental conditions, while statistically significantly different, did not exhibit a large empirical difference (8\% vs. $10 \%)$.

\section{Glove Tears}

\section{Tear Size}

Glove tears were modeled as the cumulative tear size for all used gloves (Table 4). Specifically, the size of any tear (rated 0-10) for any glove was summed across all gloves used for a given procedure. Hence, each student produced data at four time periods, the cumulative glove tear sizes for the dominant and dependent hands under the control and experimental conditions. A generalized linear mixed model (Poissonlinked) was fit to compare treatment conditions and make other comparisons as well. The results of these comparisons are in the following list: Control and experimental hands did not significantly differ overall $(p=0.95)$ 
The dominant hand had significantly larger tears than the dependent hand overall

$$
(\mathrm{p}<0.0001)
$$

The interaction of hand type (dominant/dependent) with experimental condition

(rings/no rings) was non-significant $(\mathrm{p}=0.22$ )

Analyzing within each of the hands...

In the dependent hand, wearing rings resulted in smaller tears $(0.48 v s .0 .65)$, but the effect was non-significant $(\mathrm{p}=0.27)$

In the dominant hand, wearing rings resulted in larger tears (1.42 vs. 1.21), but the effect was non-significant $(p=0.49)$

Analyzing within each of the treatment conditions...

With no rings, the dominant hand had significantly larger tears $(1.21$ vs. $0.65, \mathrm{p}=$ $0.01)$

With rings, the dominant hand had significantly larger tears $(1.42 v s .0 .48, \mathrm{p}=$ $0.0004)$

In summary, the dominating characteristic of glove tear size was the hand, i.e., dominant or dependent. The dominant hand had significantly larger tears than the dependent hand overall $(p<0.0001)$, as well as with no rings $(p=0.01)$ and with rings $(p=0.004)$. The interaction between hand type and experimental condition was nonsignificant. 
Table 4 . Values in the table are raw averages of tear size on a 0 -10 rating scale.

\begin{tabular}{|l|c|c|c|}
\hline & Dependent hand & Dominant hand & Overall \\
\hline No rings & 0.65 & 1.21 & 0.93 \\
\hline Rings & 0.48 & 1.42 & 0.94 \\
\hline Overall & 0.56 & 1.31 & 0.94 \\
\hline
\end{tabular}




\section{Presence of Tears (Binomial Outcome)}

The presence of a glove tear was modeled as a binary outcome - whether or not a tear occurred in any of the gloves used in a given procedure. As before, each student produced data at four different time periods. As with tear size, a generalized linear mixed model was fit, in this case with the binomial rather than Poisson link (to model binary outcomes). The results are shown below in (Table 5): 
Table 5 . Values in the table are raw averages of the presence of tear on a 0 -10 rating scale.

\begin{tabular}{|l|c|c|c|}
\hline & Dependent hand & Dominant hand & Overall \\
\hline No rings & $21 \%$ & $31 \%$ & $27 \%$ \\
\hline Rings & $23 \%$ & $52 \%$ & $38 \%$ \\
\hline Overall & $22 \%$ & $42 \%$ & $33 \%$ \\
\hline
\end{tabular}


The experimental hand was significantly more likely to tear than the control hand overall $(\mathrm{OR}=1.4, \mathrm{p}=0.02)$

The dominant hand was significantly more likely to tear than the dependent hand

$$
\text { overall }(\mathrm{OR}=1.9, \mathrm{p}<0.0001)
$$

The interaction of hand type (dominant/dependent) with experimental condition

$$
\text { (rings/no rings) was non-significant }(\mathrm{p}=0.29)
$$

Analyzing within each of the hands...

In the dependent hand, wearing rings did not significantly increase the likelihood of

$$
\text { tears }(\mathrm{OR}=1.1, \mathrm{p}=0.70)
$$

In the dominant hand, wearing rings significantly increased the likelihood of tearing

$$
(\mathrm{OR}=1.7, \mathrm{p}=0.02)
$$

Analyzing within each of the treatment conditions...

With no rings, the dominant hand was significantly more likely to tear ( $\mathrm{OR}=1.5$,

$$
\mathrm{p}=0.05)
$$

With rings, the dominant hand was significantly more likely to tear $(\mathrm{OR}=2.3$,

$$
\mathrm{p}=0.007)
$$

As with cumulative tear size, the dominating characteristic of the presence of tears was the hand - dominant or dependent. While the interaction of hand and experimental condition was non-significant, there were significant comparisons of the treatment conditions - overall and within the dominant hand. Further, the likelihood of tearing with rings was significantly inflated in the dominant hand. 


\section{Glove Leaks}

Leak Size

Glove leaks were modeled as the cumulative leak measurement for all used gloves. Specifically, the size of any leak (rated 0-10) for any glove was summed across all gloves used for a given procedure. Hence, each student produced data at four time periods, the cumulative leak sizes for the dominant and dependent hands under the control and experimental conditions. A generalized linear mixed model (Poisson linked) was fit to compare treatment conditions and make other comparisons as well. The results of these comparisons are in the following list (see Table 6): 
Table $\underline{6}$. Values in the table are raw averages of the leak size on a $0-10$ rating scale.

\begin{tabular}{|l|c|c|c|}
\hline & Dependent hand & Dominant hand & Overall \\
\hline No rings & 0.33 & 0.58 & 0.47 \\
\hline Rings & 0.81 & 1.17 & 0.97 \\
\hline Overall & 0.57 & 0.88 & 0.72 \\
\hline
\end{tabular}


Rings hands had significantly larger leaks than non-ringed hands overall

$(\mathrm{p}<0.0001)$

The dominant hand had significantly larger leaks than the dependent hand overall

$(\mathrm{p}=0.006)$

The interaction of hand type (dominant/dependent) with experimental condition

(rings/no rings) was non-significant $(\mathrm{p}=0.69)$

Analyzing within each of the hands...

In the dependent hand, rings were associated with larger leaks $(\mathrm{p}=0.002)$

In the dominant hand, rings were associated with larger leaks $(\mathrm{p}=0.005)$

Analyzing within each of the treatment conditions...

With no rings, the dominant hand was associated with larger leaks $(\mathrm{p}=0.02)$

With rings, the dominant and dependent hands did not significantly differ with respect

to leaks $(\mathrm{p}=0.18)$

In summary, glove leaks were significantly larger in the ring hand than in the non-ring hand, and larger in the dominant hand than in the dependent hand. These variables did not significantly interact. The presence of rings seemed to be the more important factor with respect to leaks.

Presence of Tears (Binomial Outcome)

This analysis is identical to the analysis of the presence of tears, since the presence of glove leaks directly corresponded to the presence of glove tears. 


\section{DISCUSSION}

Oral streptococci of different species were observed but not differentiated in the CFU count. There were two defining characteristics of the microbial count data, which complicated a direct analysis. The first was the "zero-inflation" of the data, i.e., $73 \%$ of the 1600 samples grew no streptococci (had counts of zero). While there are methods for analyzing zero-inflated count data such as these, generalizations to a repeated measures setting are more difficult. The second complicating statistical factor is the heavy right skewness. Twelve observations exhibited counts in excess of 1000 (confluence of microbial growth). This has the effect of eliminating mean-based inference as a reasonable method for analyzing the data. For example, although $73 \%$ of the samples had no bacteria, the average bacterial count for all the data was 25.3; conversely, the median was zero. Hence, traditional methods based upon means (or even medians) will likely perform poorly with these data, and are poor measures of central tendency.

Therefore, there was no direct analysis of the counts themselves. Rather, the outcome was a derived variable - whether or not a sample was contaminated with bacteria, i.e., count $>0$. The analysis of this outcome was a binomial-linked generalized linear mixed model, including time point, experimental condition, and handedness as factors. This has the effect of greatly simplifying the analysis and resulting conclusions, which are in terms of the likelihood of contamination rather than the "size" of the 
contamination itself. It also may dilute potentially valuable information about the colony counts, but given the issues of zero-inflation and heavy skewness above, it would be very difficult to derive reasonable conclusions about these outcomes themselves.

The raw data formed a dichotomous distribution, so further analysis was performed on the CFU data assuming that counts of microbial colonies of less than ten were evidence of essentially no growth at all; scores greater than ten were seen as evidence of significant growth. The justification for this is as follows. Under microscopic observation, many dish quadrants contained debris from the samples taken from under the rings and between the fingers, many of which had a few groups of what appeared to be solitary or very small clusters of microbes that did not grow out to form microbial plaques. Many of them also took up the blue dye in the Difco ${ }^{\mathrm{TM}}$ medium, but little or no growth was evident. The decision was made to consider low counts $(<10)$ as evidence of no growth or contamination.

In dental clinical treatment sessions, students using PROVON ${ }^{\circledR}$, an antimicrobial hand washing lotion, showed significantly fewer oral streptococcal counts on the hands with no rings than with rings. To determine the risk factors for hand contamination, it was found that students wearing rings retain oral streptococci even after post-washing after finishing their dental treatment sessions. It was also noticed that the incidence of glove tears on the hands with rings was the main route for cross-contamination. This study has enhanced the information on hand and glove contamination by showing that 1) hands wearing finger rings under gloves were more likely to be contaminated with oral streptococci after clinical dental procedures (both the raw data and the modified 
data $(\geq 10$ CFUs $)(p=0.04) .2)$ PROVON $^{\circledR}$ antimicrobial lotion, used in the dental clinics, acted less effectively on hands with rings at the four different time periods $(p<$ $0.0001)$; 3) Dental HCWs increased contamination to their hands by wearing two finger rings while performing dental treatment on patients $(p=0.04)$; 4$)$ Leakage and tears in the gloves leads to hand contamination ( $p=0.02$ for the non-ringed dominant hand, and $p=0.005$ ) for the ringed dominant hand); and 5) The dominant hand was more likely than the dependent hand to be exposed to oral fluids due to glove tears while treating patients with sharp or rotary instruments $(p=0.05$ without rings and $p=0.007$ without sharp or rotary instruments).

The general trend of CFUs found in this study is drifted downward over time. This may have been due to students entering the clinic with dirty hands from various activities and without having a chance to wash (three of the four highest readings were during the pre-wash sampling). It was surprising not to see a rise in CFUs after completing the dental procedure. The only group which did increase after the dental procedure was the dependent-no ring hand. All values fell after the post-wash after the dental procedures were completed.

It was found in the first analysis that, when the oral streptococci count was more than zero and less than ten, the dominant hand was less likely to be contaminated ( $p=$ 0.01 ) after the pre-wash using PROVON ${ }^{\circledR}$. After the post-wash, the dominant hands showed a significant decrease in contamination $(p=0.004)$ and ringed hands were significantly more likely to be contaminated $(p=0.02)$. 
All the gloves were collected from the students after the procedures and measured for tears and leakage on a 0-10 rating scale. Differences in tear size between dominant and dependent hands are larger overall for the dominant hand $(p=0.0001)$, and on the hands with rings $(p=0.007)$ compared with no rings $(p=0.05)$ in contrast to the results of Tami et al. (2006). Glove leakage was significantly larger on the ring hands than the non-ring hands, and larger on dominant than dependent hands. In addition, there was a surprisingly large number of tears and leaks in the nitrile gloves used in this study. $79.8 \%$ of right-hand gloves had tears or pre-existing holes, and $80.4 \%$ had leaks. Similarly, $70.5 \%$ of left-hand gloves had tears and $71.6 \%$ had leaks. These differences are in the correct direction. The difference between ratings for tears and leaks may have arisen by missing a small hole in a glove in the tear counting, which showed up in the leak test.

Despite the large incidence of tears and leaks found (70-80\%), the amount of streptococcal contamination is relatively small (5-15\%). Many tears occurred near the distal phalange (finger tips) from sharp or rotary instruments. The finger rings, however, are worn on the proximal phalange, which is some distance from the finger tips. An additional cause might be failure of the patients' saliva to always penetrate the tear or leak, and lodge between the fingers and under the rings where measurements were made. Students were instructed to remove and replace gloves, and wash their hands, whenever a tear or leak was noticed, so fresh saliva might not have been available in the short period of time before glove replacement. Nevertheless, once a tear occurs, the possibility remains for hands, especially under finger rings, to become contaminated with oral microbes. 
This study had $20 \%$ of students who were left handed, which is much higher than the general population (7-10\%). The glove usage was almost equal 364 right-hand and 367 left-hand $(99.7 \%)$. This reflects dental clinic policy which requires that both gloves be removed when leaving the treatment cubicle. Tears and leaks in the gloves were not recorded during the clinic sessions but were measured at the end of each clinic session by the investigator. Small holes or tears might have become larger during glove removal. Only $29.7 \%$ of students used hot water whereas $70.3 \%$ used cold water when washing with soap. The temperature of the water was variable as instant hot water was not always available. The $\mathrm{CDC}$ and recommends that the hands should be washed for 15 seconds with soap using hot water.

It is unknown whether wearing rings by dental HCWs during treatment sessions inoculates the patients with microbes from the student dentists' hands because crosscontamination in this direction was not tested. It was shown that HCWs hands with rings retain oral streptococci, presumably from their patients' mouths, even after postwash, which leads to contamination of the hands and may affect the dental students' health in one way or the other.

\section{CONCLUSIONS}

Wearing rings with or without embedded stones, perforations, crevices, or sharp edges under nitrile non-sterile exam gloves, while performing dental treatment procedures, resulted in oral streptococcus retention after dental treatment and even after washing after glove removal (post-wash). There were significantly more glove tears and leakage in the glove on the dominant hand, especially when wearing rings (experimental condition). Students used cold water to wash their hands $70 \%$ of the time 
despite CDC recommendations to use hot water. Glove usage was almost identical for left and right hands, but $79.8 \%$ of right-hand gloves had tears or pre-existing holes, and $80.4 \%$ had leaks, while $70.5 \%$ of left-hand gloves had tears and $71.6 \%$ had leaks.

Wearing rings under gloves should be prohibited.

\section{FUTURE STUDIES}

1. Sample only twice before and after dental procedures to observe contamination of the hand. This gives up measuring the effectiveness of hand washing, however.

2. Measure soap \& water cleansing compared to hand sanitizer (easier to re-glove after alcohol-based hand sanitizer quickly evaporates).

3. Distinguish between rings with stones, broad rings, and narrow rings with respect to microbial contamination.

4. Provide rings to students more than a day ahead before the treatment session and not one day so that they become truly contaminated with microbes.

5. Limit the clinical disciplines to operative dentistry, prosthodontics, endodontics, oral surgery and periodontal surgery, where sharp/rotary instruments are used.

6. Avoid contamination of the prepared medium by airborne spores. Renovation of the dental school building may have been the cause of some fungal contamination of dishes, but this did not affect the counts of oral streptococci because of the fungal morphology, lack of uptake of blue dye, and slow growth. 


\section{REFERENCES}

Alur, A.A., Rane, M.J., Scheetz, J.P., Lorenz, D.J., Gettleman, L. (2009). Stimulated microbe removal around finger rings using different hand sanitation methods. International Journal of Oral Science. 1(3), 138-44.

Alp, E., Haverkate, D., Voss, A. (2006). Hand hygiene among laboratory workers. Infection Control and Hospital Epidemiology 27(9), 978-980.

Aly, R., and Maibach, H.I. (1988). Comparative antibacterial efficacy of a 2-minute surgical scrub with chlorhexidine gluconate, povidone-iodine, and chloroxylenol sponge-brushes. American Journal of Infection Control 16(4), 173-177.

Bartlett, G.E., Pollard, T.C., Bowker, K.E., Bannister, G.C. (2002). Effect of jewelry on surface bacterial counts of operating theatres. Journal of Hospital Infection 52(1), 68-70.

Carlsson, J. (1967). A medium for isolation of streptococcus mutans. Archives of Oral Biology 12, 1657-87.

Centers for Disease Control \& Prevention. (2002). Guideline for Hand Hygiene in Health-Care Settings: Recommendations of the Healthcare Infection Control Practices Advisory Committee and the ICPAAC/SHEA/APIC/IDSA. Hand Hygiene Task Force, Morbidity and Mortality Weekly Report (MMWR) 51(16), 29-34.

Centers for Disease Control and Prevention. (2002). Guidelines for hand hygiene in health-care settings (2002). Recommendations of the Healthcare Infection Control Practices Advisory Committee and the HICPAC/SHEA/APIC/IDSA Hand Hygiene Task Force 51(16), 30-33.

Centers for Disease Control and Prevention (1999). Nosocomial group A streptococcal infections associated with asymptomatic health-care workers--Maryland and California. Morbidity and Mortality Weekly Report (MMWR) 48(8), 163-166.

Fagernes, M., Lingaas, E., Bjark, P. (2007). Impact of a single plain finger ring on the bacterial load on the hands of healthcare workers. Infection Control and Hospital Epidemiology 28(10), 1191-1195. 
Field, E.A., McGowan, P., Pearce, P.K., Martin, M.V. (1996). Rings and watches: should be removed prior to operative dental procedures? Journal of Dentistry 24(1-2), 65-69.

Harte, J.A. (2004). Looking inside the 2003 CDC dental infection control guidelines. Journal of the California Dental Association 32(11), 919-930.

Hayes, R.A., Trick, W.E., Vernon, M.O., Nathan, C., Peterson, B.J., Segreti, J., Pur, S.L., Schmitt, B.A., Rice, T.W., Welbel, S.F., Weinstein, R.A. (2001). Ring use as a risk factor for hand colonization in a surgical intensive care unit. Interscience Conference on Antimicrobial Agents and Chemotherapy 41: abstract No. K-1333.

Hoffman, P.N., Cooke, E.M., McCarville, M.R., Emmerson, A.M. (1985). Microorganisms isolated from skin under wedding rings worn by hospital staff. British Medical Journal 290(6463), 206-207.

Jacobson, G., Thiel, J.E., McCune, J.H., Farrell, L.D. (1985). Handwashing: ringwearing and number of microorganisms. Nursing Research 34(3), 186-188.

Kakis, A., Gibbs, L., Eguia, J., Kimura, J., Vogelei, D., Troup, N., Stevens, D., Kaplan, E.L., Johnson, D.R., Conte, J.E. (2002). An outbreak of group A Streptococcal infection among health care workers. Clinical Infectious Diseases 35(11), 1353-1359.

Kelsall, N.K., Griggs, R.K., Bowker, K.E., Bannister, G.C. (2006). Should finger rings be removed prior to scrubbing for theatre? Journal of Hospital Infection 62 (4), 450-452.

Kennedy, A.M., Elward, A.M., Fraser, V.J. (2004). Survey of knowledge, beliefs, and practices of neonatal intensive care unit health-care workers regarding nosocomial infections, central venous catheter care, and hand hygiene. Infection Control and Hospital Epidemiology 25(9), 747-752.

Larson, E. (1988). Guideline for use of topical antimicrobial agents. American Journal of Infection Control 16:253-66.

Larson, E., Mayur, K., Laughon, B.A. (1989). Influence of two handwashing frequencies on reduction in colonizing flora with three handwashing products used by health care personnel. American Journal of Infection Control 17(2), 83-88

Larson, E., Talbot, G.H, (1986). An approach for selection of health care personnel hand washing agents. Infection Control 7:419-24.

Lowbury, E.J.L. (1968). Aseptic methods in the operating suite. Lancet 1(7545), 705-709. 
Montville, R., Chen, Y., Schaffner, D.W. (2002). Risk assessment of hand washing efficacy using literature and experimental data. International Journal of Food Microbiology 73(2-3), 305-313.

Nikawa, H., Hamada, T., Tamamoto, M., Abekura, H., Murata, H. (1996). Perforation of dental gloves during prosthodontic treatments as assessed by the conductivity and water inflation tests. International Journal of Prosthodontics 9(4), 362-6.

Patel, H.B., Fleming, G.J., Burke, F.J. (2003). A preliminary report on the incidence of pre-existing pinhole defects in nitrile dental gloves. British Dental Journal 195(9), 509-512.

Paulson, D.S. (1994). Comparative evaluation of five surgical hand scrub preparations. AORN Journal 60(2), 246-256.

Rupp, M.E., Fitzgerald, T., Puumala, S., Anderson, J.R., Craig, R., Iwen, P.C., Jourdan, D., Keuchel, J., Marion, N., Peterson, D., Sholtz, L., Smith, V. (2008). Prospective, controlled, cross-over trial of alcohol-based hand gel in critical care units. Infection Control and Hospital Epidemiology 29(1), 8-15.

Salisbury, D.M., Hutfilz, P., Treen, L.M., Bollin, G.E., Gautam, S. (1997). The effect of rings on microbial load of health care workers' hands. American Journal of Infection Control 25(1), 24-27.

Tami, R., Waterman, Smeak, D.D., Kowalski, J., D.V.M., Diplomate, A.C.V.M., and Hade, E.M. (2006). Comparison of bacterial counts in glove juice of surgeons wearing smooth band rings versus those without rings. American Journal of Infection Control 34 (7), 421-425.

Trick, W.E., Vernon, M.O., Hayes, R.A., Nathan, C., Rice, T.W., Peterson, B.J., Segreti, J., Welbel, S.F., Solomon, S.L., Weinstein, R.A. (2003). Impact of ring wearing on hand contamination and comparison of hand hygiene agents in a hospital. Clinical Infectious Diseases 36(11), 1383-1390.

Wongworawa, M.D., and Jones, S.G. (2007). Influence of rings on the efficacy of hand sanitization and residual bacterial contamination. Infection Control and Hospital Epidemiology 28(3), 351-353.

www.reliablepaper.com/PROVON_Antimicrobial_Lotion_Soap_w_Chloroxylenol_p/g oj4218-12.htm

www.bd.com/ds/technicalCenter/inserts/Mitis_Salivarius_Agar.pdf

Yildirim, I., Ceyhan, M., Cengiz, A.B., Bagdat, A., Barin, C., Kutluk, T., Gur, D. (2008). A prospective comparative study of the relationship between different types of ring and microbial hand colonization among pediatric intensive care unit nurses. International Journal of Nursing Studies 45(11), 1572-1576. 


\title{
Appendix A:
}

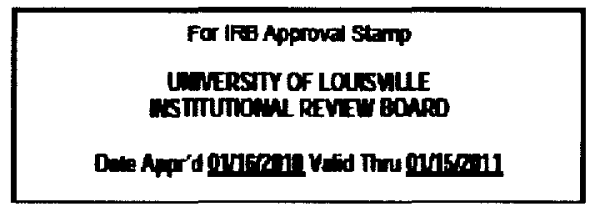

\section{SUBJECT INFORMED CONSENT DOCUMENT}

\author{
Effect of Finger Rings on Microbial Cross-Contamination \\ During Dental Clinical Procedures
}

IRB assigned number: 09.0416

Investigator(s) name \& address: Lawrence Gettleman, DMD, MSD. University of Louisville, School of Dentistry, 501 S. Preston St., Room L 35-U, Louisville, KY 40292

Site(s) where study is to be conducted: University of Louisville, School of Dentistry, 501 S. Preston Street, Louisville, KY 40292

Phone number for subjects to call for questions: (502) 852-1185

\section{Introduction and Background Information}

You are invited to take part in a research study because it is important to know if wearing finger rings (jewelry) can have an effect on cross contamination of microbes from the patient to you, and vice versa. The study is being conducted under the direction of Lawrence Gettleman, DMD, MSD, and Swapna Nadikuda, BDS, an Oral Biology student. Approximately 50 local subjects (dental students) will be invited to participate. Your participation in this study will last for 2 to 3 hours during two regular University of Louisvile School of Dentistry student clinic sessions.

\section{Purpose}

The purpose of this study is to determine if bacteria from a patient's mouth will accumulate under jewelry when wom under disposable gloves that may tear or leak during operative and fixed prosthodontic dental procedures.

\section{Procedures}

You will be chosen to participate in this study if you wear finger rings on any finger except the thumb of one or both hands. We will supply additional rings for you to use for purposes of this study. Your rings may be loose or tight, or may have a stone setting. Participation in two clinic sessions ( $21 \%-3$-hours) is required. You will be asked to fill out a form with your name, student number, the clinical procedure to be carried out and complete several questionnaires related treatment procedures to your patients. These include 1. What is the chief complaint of the patient? 2. Type of treatment procedure performed? 3. Duration of the procedure? 4. How many gloves have they changed during the procedure and why? Information of your patient will not be recorded. 
IRB \# : 0.0416 / Effect of Finger Rings on Mrorobial Cross-Contamination Duing Dental Clinical Procedures

The procedures involve routine dental operations provided by $3^{m}$ and $4^{\text {th }}$ year dental students to regular clinical patients in the restorative and prosthetic clinics. We will take microbial samples between two fingers on each hand that have the rings or the two hands without the rings, before and after your hands are washed using Provon soap and/or alcoholbased hand sanitizer for 15 seconds following procedures in the ULSD Clinic Manual. You will then use non-sterile nitrile exam gloves and perform routine procedures on your patient. If the gloves need to be changed, we will keep track of the number of gloves used and will collect them, and will record why the glove(s) were changed. After the dental procedures are complete, we will take another set of microbial swab samples to determine the quantity and retaining capacity of Streptococcus bacteria under rings before and after your hands are washed using Provon soap and/or alcohol-based hand sanitizer for 15 seconds. A total of eight swabs per subject per clinic session will be obtained to measure the effectiveness of hand hygiene when finger rings are wom under gloves. The samples will be cultured and evaluated.

\section{Potential Risks}

There are no known physical risks linked to this study.

\section{Benefits}

The information gathered from this study will not directly benefit you, but the data will be helpful to others in investigating cross-contamination curing dental clinical procedures.

\section{Altematives}

Instead of taking part in this study, you could choose to carry out your regular clinical procedure as done any other day.

\section{Research-Related injury}

If you are injured by being in this research study, the study doctor will arange for you to get medical treatment. The study site, or your study doctor has not set aside money to pay for treatment of any injury. You and your insurance company will be biled for the treatment of these injuries. Before you agree to take part in this research study you should find out whether your insurance will cover an injury in this kind of research. You should talk to the study doctor or staff about this. If you are injured, there is no money set aside for lost wages, discomfort, disability, 8c. You do not give up your legal rights by signing this form. If you think you have a research-related injury, please call Lawrence Gettleman, DMD, MSD, at (502) 852-1185.

\section{Compensation}

You will not be compensated for your time, inconvenience, or expenses \&c. while you are in this study.

\section{Costs}

If you are injured by the research, there may be additional cost for participating in the research. Otherwise there will be no additional cost to you.

Consent version date_January 11, 2010 
IRB \# : 09.0418/ Effect of Finger Rings on Microbial Cross-Contamination During Dental Clinical Procedures

Confidentiality

Total privacy cannot be guaranteed. We will protect your privacy to the extent permitted by law. If the results from this study are published, your name will not be made public. The identity of your patient will not be recorded in this study. The following may look at your research and medical records:

- The University of Louisville Institutional Review Board, Human Subjects Protection Program Office, Privacy Office and others involved in research administration at the University

- People who are responsible for research and HIPAA oversight at the institutions where the research is conducted

- Government agencies, such as:

- Office for Human Research Protections

o Office of Civil Rights

Security

Your data will be kept private by being physically secured and in a passwrord-protected computer or secured server.

\section{Conflict of Interest}

This study does not involve a conflict of interest because the institution and investigator will not be compensated for your participation.

Voluntary Participation

Taking part in this study is completely voluntary. You may choose not to take part at all. If you decide not to be in this study, you won't be penalized or lose any benefits for which you qualify. If you decide to be in this study, you may change your mind and stop taking part at any time. If you decide to stop taking part, you won't be penalized or lose any benefits for which you qualify.

You will be told about any new information leamed during the study that could affect your decision to continue in the study.

\section{Termination}

Your study doctor has the right to stop this study at any point. Your study doctor may take you out of this study with or without your okay for unknown reasons at any time.

\section{Participation in Other Research Studies}

You may take part in this study if you are currentty in another research study. It is important to let your doctor know if you are in another research stucty.

\section{Contact Persons}

If you have any questions, concerns, or complaints about the research study, please contact Dr Lawrence Gettleman at (502) 852-1185.

Consent version date_Jaruary 11, 2010

Page 3 of 4 
IRB : 09.04 10 / Effect of Finger Rings on Microbial Cross-Contamination During Dental Clinical Procedures

Research Subject's Rights

If you have any questions about your rights as a research subject, you may call the Human Subjects Protection Program Office at (502) 852-5188. You may discuss any questions about your rights as a research subject, in private, with a member of the Institutional Review Board (IRB). You may also call this number if you have other questions about the research, and you cannot reach the study doctor, or want to tak to someone else. The IRB is an independent committee made up of people from the University community, staff of the institutions, as well as people from the community not connected with these institutions. The IRB has reviewed this research study.

\section{Concems and Complaints}

If you have concerns or complaints about the research or research staff and you do not wish to give your name, you may call the toll-free number (877) 852-1167. This is a 24-hour hot line answered by people who do not work at the University of Louisville.

\section{Acknowledgment and Signatures}

This informed consent document is not a contract. This document tells you what will happen during the study if you choose to take part. Your signature indicates that this study has been explained to you, that your questions have been answered, and that you agree to take part in the study. You are not giving up any legal rights by signing this informed consent document. You will be given a copy of this consent form to keep for your records.

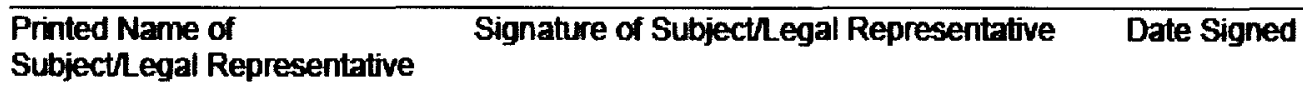

\begin{tabular}{lll}
\hline Printed Name of Person & Signature of Person Explaining & Date Signed \\
Explaining Consent Form & Consent Form (if other than the Investigator) &
\end{tabular}

\begin{tabular}{lll}
\hline Printed Name of Investigator & Signature of Investigator & Date Signed
\end{tabular}

\section{LIST OF INVESTIGATORS \\ PHONE NUMBERS}

Lawrence Gettleman, DMD, MSD

Swapna Nadikuda, BDS

Consent version date January 11, 2010
(502) $852-1185$

(502) 852-1185

For IF Approval stamp

in MEDTY OF LOTSUUE CoITIUTOWN REVEW BOMno

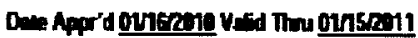


AUTHORIZATION FOR USE AND DISCLOSURE OF YOUR HEALTH INFORMATION FOR RESEARCH

\begin{tabular}{|c|c|c|}
\hline IRB\#: & \multirow{2}{*}{\multicolumn{2}{|c|}{$\begin{array}{l}\text { Study Tite } \\
\text { Effect of Finger Rings on Microbial Cross-contamination } \\
\text { During Dental Clinical Procedures }\end{array}$}} \\
\hline 09.0416 & & \\
\hline \multicolumn{3}{|c|}{ PRINCIPAL INVESTIGATOR/PROJECT DIRECTOR (PI/PD) } \\
\hline \multicolumn{2}{|c|}{$\begin{array}{l}\text { Name (Last Name, First Name, MI) } \\
\text { Gettleman, Lawrence }\end{array}$} & gettlemanoloricrillecedu \\
\hline \multirow{3}{*}{\multicolumn{2}{|c|}{$\begin{array}{l}\text { Mailing Address - Include University } \\
\text { Denatment (if andicable) } \\
\text { Dept. of Oral Health \& Rehabilitation } \\
\text { School of Dentistry } \\
501 \text { S. Preston St., Rm. LL 35-U } \\
\text { Louisville, KY } 40292\end{array}$}} & $\begin{array}{l}\text { Telephone Number } \\
\text { (502) } 852-1185\end{array}$ \\
\hline & & $\begin{array}{l}\text { Pager/Cell Phone Number } \\
\text { (502) } 727-7244\end{array}$ \\
\hline & & $\begin{array}{l}\text { Fax Number } \\
(502) 852-7573\end{array}$ \\
\hline
\end{tabular}

Please read this form before you sign it.

In our research, we will look at and may share information about you and your health. Federal law requires that health providers and researchers protect this information and keep it private (confidential). "We" or "us" in this document refers to the following places (institutions, facilities, and practices) that are checked ( $r$ ).

Affiliated sites

\begin{tabular}{|c|c|c|c|}
\hline$[\sqrt{n}]$ & $\begin{array}{l}\text { University of Louisville (Do not remove this } \\
\text { check.) }\end{array}$ & {$[1]$} & Louisville Metro Public Health \& Welliness \\
\hline T] & Jewish Hospital \& St. Mary's Healthcare & TI & KY Cabinet for Health \& Family Services \\
\hline T] & $\begin{array}{l}\text { Norton Healthcare, Inc., induding Kosair } \\
\text { Children's Hospital }\end{array}$ & 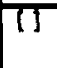 & Seven Counties Services \\
\hline [] & $\begin{array}{l}\text { University of Louisville Hospital/J. Graham } \\
\text { Brown Cancer Center }\end{array}$ & [ ] & Other(s): \\
\hline
\end{tabular}

University of Louisville Reseanch Foundation (ULRF) Clinical Sites

\begin{tabular}{|l|l|l|l}
\hline [ ] & Children 8 Youth Clinic & (1) UL Pathology Fow Cytometry Lab (BCC)
\end{tabular}

j) doctoral Perio, Endo and Ortho; Oral Surgery and GPR at ACB; Uof. Dental Associates, Postdoctoral Pediatric Dentistry Clinic)

(1) Family Medicine - (Newburg and Central Station; also Geriatrics and Sports Medicine at Central Station)

(1) Harambee Nursing Center

[ ] Kidney Disease Program (Dialysis Unit and UL Renal Transport Lab)

(1) Neonatal Follow Up Program

\begin{tabular}{|l|l|}
\hline If & UL Pathology Special Procedures Lab \\
\hline [1 & University Health Services (HSC and Belknap) \\
\hline II & Weisskopf Child Evaluation Center \\
\hline II & $\begin{array}{l}\text { WHAS Crusade For Children Audiology \& Speech } \\
\text { Pathology Center }\end{array}$ \\
I] & WTWGS Clinic - (ACB) \\
\hline
\end{tabular}

Faculloy Practice Group Sites

\begin{tabular}{|c|c|c|c|}
\hline [1] & University Anesthesiology Associates, PSC & T) & $\begin{array}{l}\text { University Pediatrics Foundation, Inc. d/b/a } \\
\text { University Child Health Specialists, Inc. (UCHS) }\end{array}$ \\
\hline [] & University Radiological Associates, PSC & {[]} & University Children's Sleep Specialists, UC \\
\hline 11 & $\begin{array}{l}\text { University Physicians Associates (UPA)/ UPG - } \\
\text { Radiology, PSC }\end{array}$ & 11 & $\begin{array}{l}\text { University Children's Infectious Disease } \\
\text { Specialists, LLC }\end{array}$ \\
\hline TI & University Emergency Medicine Associates, PSC & [1] & University Children's Kidney Specialists, ULC \\
\hline [] & University Family Practice Associates, PSC & {$[1$} & University Children's Sedation Service, ШC \\
\hline [] & University Physicians Assogiates (UPA), PSC & {[]} & University Pediatric Endocrinology, LC \\
\hline [] & University Medical Associates, (UMA), PSC & T) & Bone Marrow Transplant, LLC \\
\hline [] & Associates in Dermatology, PLLC & {[]} & Neonatal Associates, PSC \\
\hline II & University Neurologists, PSC & {$[1$} & Pediatric \& Perinatal Pathology Assogiates, PSC \\
\hline
\end{tabular}




\begin{tabular}{|c|c|c|c|}
\hline & Neurosurqical Insbitute of Kentudky, PSC & {[]} & Pediatric Cardioloqy Associates, PSC \\
\hline & University GYN/OB Foundation, Inc. & {[]} & Pediatric Hematology/Oncology Specialists, PSC \\
\hline [] & University OB/GYN Associates, PSC & {[]} & Pediatric Pulmonary Medicine, PSC \\
\hline [] & $\begin{array}{l}\text { Ophthalmological Services, Inc. - Primary Eye } \\
\text { Clinic }\end{array}$ & (1) & University Psychiatric Foundation, Inc. \\
\hline [1] & Eye Specialists of Louisville, PSC & [1] & University Psychiatric Services, PSC \\
\hline [] & Kentudky Vision Center, Inc. & {[]} & University Radiotherapy Associates, PSC \\
\hline [] & Shea, Tillett, Malkani, Caborn, PSC & {[]} & University Surgical Associates, PSC \\
\hline T] & Spine Institute, PSC & [T & University Pediatric Surgery Associates, PSC \\
\hline [] & Orthopedic Trauma Associates, PSC & 【] & $\begin{array}{l}\text { University Cardiathoracic Surgical Associates, } \\
\text { PSC }\end{array}$ \\
\hline [] & University Pathologists, PSC & {$[1$} & Universiby Unalogy, PUC \\
\hline & Louisville Pathology Laboratory & & Other: \\
\hline
\end{tabular}

The law allows us to look at and share your health information for research, if you agree to let us do this and if we protect it as required.

This form explains how we will look at and share your health information, as well as, who may see it and use your information. If you sign this form, it means you are letting us look at and share information for research.

1. Health information about you from the items checked below may be looked at or given out to others.

[ ] Consultation reports

(1) Diaries and questionnaires

[] Discharge summaries

I Records of your operation(s)

(1) Medical progress notes

(1) Healthcare provider orders

(1) History and physical exams

(1) Laboratory, x-ray, and other tests

( ) Photos, videotapes, or digital or other images

(1) Records about the study device

[1 Records about the study drug and other drugs you may be taking

[ ] Other:

$\mathbf{X}$ WE WILL NOT BE LOOKING AT ANY OF THE ITEMS LISTED BELOW FOR THIS STUDY.

OR

[ ] THE INFORMATION WE MAY LOOK AT OR GATHER FOR THIS RESEARCH MAY INCLUDE:

(1) HIV / AIDS status

(1) Hepatitis infection

(1) Sexually transmitted diseases

(1) The diagnosis and treatment of a mental health condition

(1) Other reportable infectious diseases

2. The following people or groups may share, receive and/or look at your information: The people and organizations listed on this form to conduct, analyze, and understand this study;

The University of Louisville Institutional Review Board, Human Subjects Protection Program Office, Privacy Office and others involved in research administration at the University

- People who are responsible for research and HIPAA oversight

- Govemment agencies, such as:

- Office for Human Research Protections

- Office of Civil Rights

- In addition, the groups chedked below may share, receive and/or look at your Form: Reseurch Muthortation - FWMAL (Rev 02-16-09)

Page 2 of 4 Imvesipotor Revition Dete: (1anuary 11, 2010) 
information:

(1) The sponsor of the study and the people that the sponsor may contract with for the study. The name of the sponsor is:

(1) Investigators and research staff at other places that are participating in the study;

(1) An outside institutional review board (human subjects review board)

I I The Data Safety Monitoring Board

(1) Other:

If you have questions about who these people or organizations are, you may ask us.

3. While we are required to protect your health information, once any information leaves our institutions, we cannot promise that others will keep it private (confidential).

4. The information we look at or give to others as part of the research will be analyzed and further studied to answer the research questions and to make sure that the research was done correctly.

\section{You have the following rights:}

You do not have to sign this form. However, if you do not sign this form you will not be able to take part in this research. This will not change the health care or health care benefits you would otherwise receive.

You may cancel the permission you have given in this form at any time. This means you can tell us to stop using and sharing your information. If you cancel your permission:

- We will stop collecting information about you.

- You may not withdraw information that we had before you told us to stop.

- We may already have used it or shared it.

- We may need it to complete the research.

- Staff may follow-up with you if there is a medical reason to do so.

To cancel your permission, you should complete a written "Revocation of Research Authorization" form. Please send completed form to:

Institutional Review Board

MedCenter One, Suite 200

501 E. Broadway

Louisville, KY 40202

A revocation form may be obtained from your study doctor, designated personnel or from the Human Subjects Protections Program Office website (htto://louisville.edu/research/humansubjects/subject-information). If you have any questions, call the Human Subjects Protections Program Office at (502) 852-5188.

6. The time period when information can be used or shared ends when all activities related to this study are completed.

7. Your access to your health information [ ] will [ $x$ ] will not be limited during this study.

If you do not know what something means, you may ask us. Before you sign this, you may talk it over with someone you trust. You will be given a copy of this form after you have signed it.

Form: Reseer on Authoritation - FINAL (REN 02-16-09)

Page 3 of 4 
FOR ADULTS (OR MINORS) CAPABLE OF GIVING AUTHORIZATION:

\begin{tabular}{lll}
\hline Subjects Slonature & Dale Slgned & Printed Rame
\end{tabular}

FOR CHILDREN OR ADULTS NOT CAPABLE OF GIVING AUTHORIZATION:

Signture of ParentSurropoted

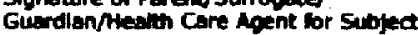

Dete Shoned

Printed Mame

Relationship of representative (Surrogate) to Subject:

NOTE: THE PRINCIPAL INVESTIGATOR MUST:

- PROVIDE A COPY OF THE signed aUTHORIZATION TO THE SUBJECT

- RETAIN THE ORIGINAL SIGNED AUTHORIZATION IN THE RESEARCH RECORD

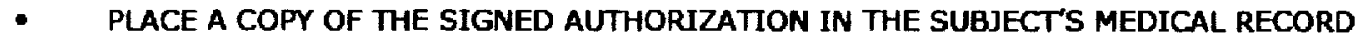

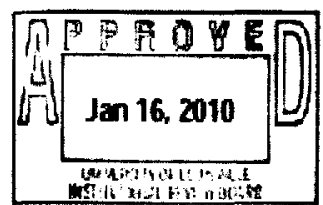

Form: Reseerch Authortwiton - FWAL (Rex 02-16-09)

Pege 4 of 4 


\begin{tabular}{|c|c|c|}
\hline $\begin{array}{l}\text { REVOCATION OF AUTHORIZATI } \\
\text { INFOR }\end{array}$ & $\begin{array}{l}\text { USE } \\
\text { N FOR } \\
\text { UIn To: }\end{array}$ & $\begin{array}{l}\text { D DISCLOSURE OF YO } \\
\text { SEARCH }\end{array}$ \\
\hline 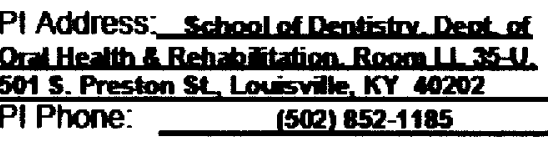 & OR & $\begin{array}{l}\text { Institutional Review Board } \\
\text { MedCenter One, Suite } 200 \\
501 \text { E. Broadway } \\
\text { Louisville, KY } 40202\end{array}$ \\
\hline
\end{tabular}

Iitle of Study: Effect of Finoer Rings on Microhial Cross-contamination Durina Dental clinical Procedures

\section{IRB 09.0416}

To Whom it Mery Concern:

I would like to discontinue my participation in the research study noted above. I understand that health information already collected will continue to be used as discussed in the Authorization I signed when joining the study.

Your options are (choose one):

$\square$ Withdraw from Study \& Discontinue Authorization:

Discontinue my authorization for the future use and disclosure of protected health information. In some instances, the research team may need to use your information even after you discontinue your authorization, for example, to notify you or govemment agencies of any health or safety concerns that were identified as part of your study perticipation.

$\square$ Withdraw from Study, but Continue Authorization:

Allow the research team to continue collecting information from my personal health information. This would be done only as needed to support the goals of the study and would not be used for pupposes other than those already described in the research authorization.

I understand that I will receive confirmation of this notice.

Signature of Subject

Siqnature of Subject Representative (if sibject unable to sign)

Printed Narne of Subject OR Subject Representative

Address

Optional:

I am ending my participation in this study because:

Form: Reseer on Authortzetion Revocaton- FILAL (Rev 2-16-09) Imvetipator Revlution Dete: (BSERT DATE OF LAST REVISION)

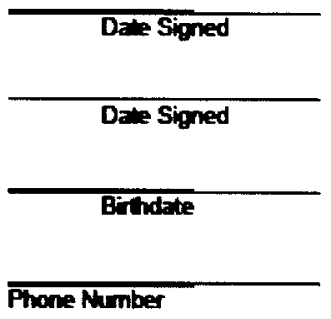

Phone Number

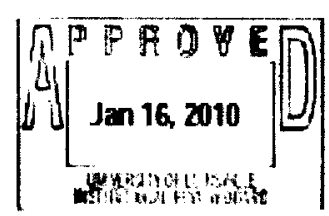

rave 2 un + 


\section{Research Subjects Needed}

Dental students older than $\mathbf{1 8}$ years of all races are needed for a research study to evaluate the effect of finger rings under examination gloves on microbial contamination during dental clinical treatment. The procedures involve routine dental operations provided by $3^{\text {trd }}$ and $4^{\text {th }}$ year dental students to regular clinical patients in the restorative and prosthetic clinics. Finger rings will be provided to students who do not wear rings, to encourage participation in the study. To determine the quantity and retaining capacity of Streptococcus bacteria under rings before and after the treatment procedures, sample swabs will be taken as follows: a) before washing the hands; b) after washing but before donning gloves; c) after finishing the dental clinical procedure; and d) after final washing of the hands. The number of gloves worn on each hand will be tallied. A total of eight swabs per subject per clinic session will be obtained to measure the effectiveness of hand hygiene when finger rings are worn under gloves. The samples will be cultured and evaluated.

Subjects will complete several questionnaires related treatment procedures to their patients. Your regular clinic appointments will range from 1-3hours.

The study's emphasis is on voluntary participation of dental students. The study will be performed in the teaching clinics at the University of Louisville, School of Dentistry.

Contact Dr. Lawrence Gettleman at (502) 852-1185 or his student, Swapna Nadikuda, at (502) 271-0953, to be screened for this study.

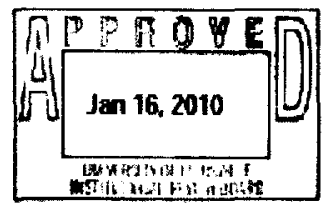




\section{Appendix $\underline{B}:$}

University of Louisville, School of Dentistry

Research Project: "Effect of Finger Rings on Microbial Cross-contamination

During Dental Clinical Procedures"

IRB No. 09.0416

\section{STUDENT EVALUATION QUESTIONNAIRE}

DATE $/ \_$_

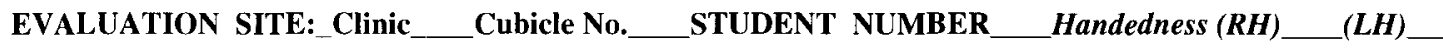

PROCEDURE TYPE: $\quad$ PROSTHETICS and RESTORATIVE DENTAL PROCEDURES

DIRECTIONS: Please answer the following questions about the dental procedure before and after the treatment process. All questions must be answered by giving a suitable reason.

\section{BEFORE DENTAL TREATMENT}

1. Chief complaint of the patient:

2. Anticipated type of treatment procedure performed and the CDT code number: Code No.

3. Anticipated duration of the treatment procedure: Hours Minutes

\section{AFTER DENTAL TREATMENT}

4. Actual type of treatment procedure performed and the CDT code number: : Code No.

5. Actual duration of the treatment procedure: Hours Minutes

6. Number of gloves changed during the procedure: Left hand Right hand

7. Reason for changing the gloves during the procedure:

Left hand

Right hand

8. Type of hand washing agent used (circle):

a. germ- $X^{\circledR}(63 \%$ ethyl alcohol based hand sanitizer $)$

b. $\operatorname{PROVON}^{\circledR}(0.3 \%$ chloroxylenol soap) and water

7. Water used (circle):

a. Cold water

b. Hot water

8. Duration of hand washing in seconds:

9. How comfortable is it to wear the rings during the dental clinical procedures?

10. In what areas do you think bacteria will reside?

11. How satisfied are you participating in this study?

12. Total time for this evaluation questionnaire: minutes.

This is the end of the STUDENT EVALUATION QUESTIONNAIRE. Thank you. 


\title{
CURRICULUM VITAE
}

\section{Swapna Nadikuda, B.D.S.}

\author{
3016 Ledge Brook Court, Louisville, Kentucky 40241
}

E-mail: swapnaram2001@gmail.com, Phone: (502) 271-0953

\section{EDUCATION}

August 2008 - present Master of Science in Oral Biology, University of Louisville, School of Dentistry, Louisville, Kentucky. GPA 3.79

December 2003 - . C C C C C.Rpulsory Rotatory Internship (C.) B.D.

December 2004 Farooqia Dental College \& Hospital, Mysore, India

September 1999 - $\quad$ BDS (Bachelor of Dental Surgery) Rajiv Gandhi

September 2003 University of Health Sciences, Mysore, Karnataka, India. GPA 3.02

April 1996 - April 1998 Board of Intermediate Education $(10+2)$, secured $82 \%$ Ratna Junior College, Hyderabad, India

March 1986 - March1996 Board of Secondary Education (10), secured 84\% St. Ann's Girls High School, Hyderabad, India

\section{RESEARCH EXPERIENCE}

August 2008 - present

"Effect of Finger Rings on Microbial Cross Contamination During Dental Clinical Procedures" with Dr. Lawrence Gettleman, D.M.D., M.S.D., Professor of Prosthodontics \& Biomaterials

January 2009 - April 2009 Project on I-CAT (Cone beam 3-D dental imaging system) images. Allan G. Farman, B.D.S., Ph.D. and William C.Scarfe, B.D.S., F.R.A.C.D.S. 


\section{WORK \& VOLUNTEER EXPERIENCE}

February 25, 2010

June 2008 - present

May 2008 - June 2008

August 2007 - present

December 2004 -

May 2007

December 2004 -

May 2007

December 2003 -

December 2004

\section{MEMBERSHIPS}

December 2003-May 2007 Indian Dental Association

August 2008 - present Associate member, Sigma Xi, The Scientific Research Society, Louisville Chapter
Participated in Smile Kentucky! dental program

Shadowing in dental office - Louisville, KY,

Bauman Nick, D.M.D. (periodontist)

Shadowed in student dental clinics, University of

Volunteer for religious services, educating people regarding oral health and dental problems. Assist leading prayer service, Hindu Temple of Kentucky, Louisville, Kentucky

Consultant dentist (full time), Yashoda Super Specialty Hospital, Hyderabad, India. Dr. Niranjan Reddy S., M.D.S.

Consultant Dentist (Volunteer work and community service) Children Heath Camp in Warangal, India, and Dental Rehabilitation Camp in Sri Vidhya

Niketan, Mothkuru, India

Consultant Dentist. (part time) Surya Dental Care, Mysore, India, Dr. Naresh Lingaraju, B.D.S., M.D.S. Louisville, School of Dentistry, Louisville, Kentucky

\section{CONFERENCES ATTENDED}

October 2008

February 2009
October 2008

\begin{abstract}
"New Aspects of Dentistry"-by Dr. Gordon Christensen, University of Louisville, School of Dentistry
\end{abstract}

"Emerging diseases \& challenging issues in infection control" by Dr. John Molinari, University of Louisville, School of Dentistry 


\section{PUBLICATIONS \& PRESENTATIONS}

April 2003

February 2006

azzperiodontitis,

Super Specialty

October 2006
Presented seminar on "Maxillary and Mandibular Fractures," Farooqia Dental College \& Hospital, Mysore, India

Paper presentation on the topics of gingivitis, and oral care. Yashoda Hospital, Hyderabad, India

Presented seminar in Children Heath Camp (Warangal, India) on dental hygiene 